\title{
Compositionally Graded SiCu Thin Film Anode by Magnetron Sputtering for
}

\section{Lithium Ion Battery}

\author{
B. D. Polat ${ }^{1 *}$, O. L. Eryilmaz ${ }^{2}$, O. Keleş ${ }^{*}$, A. Erdemir ${ }^{2}$, and K. Amine ${ }^{3}$ \\ ${ }^{1}$ Department of Metallurgical and Materials Engineering, Istanbul Technical \\ University, Maslak, Istanbul, 34469, Turkey
}

Tel: 00902122853398, Fax: 00902122853427

e-mail:ozgulkeles@itu.edu.tr and bpolat@itu.edu.tr

2 Energy Systems Division, Argonne National Laboratory, Argonne, Illinois 60439

3 Chemical Sciences and Engineering Division, Argonne National Laboratory, Argonne, Illinois 60439, USA

\begin{abstract}
Compositionally graded and non-graded composite $\mathrm{SiCu}$ thin films were deposited by magnetron sputtering technique on $\mathrm{Cu}$ discs for investigation of their potentials in lithium ion battery applications. The compositionally graded thin film electrodes with 30 at.\% $\mathrm{Cu}$ delivered a $1400 \mathrm{mAh} \mathrm{g}^{-1}$ capacity with $80 \%$ coulombic efficiency in the first cycle and still retained its capacity at around $600 \mathrm{mAh} \mathrm{g}^{-1}$ (with $99.9 \%$ coulombic efficiency) even after 100 cycles. On the other hand, the non-graded thin film electrodes with 30 at. $\% \mathrm{Cu}$ exhibited $1100 \mathrm{mAhg}^{-1}$ as the first discharge capacity with $78 \%$ coulombic efficiency but the cycle life of this film degraded very quickly, delivering only $250 \mathrm{mAhg}^{-1}$ capacity after $100^{\text {th }}$ cycles. Not only the $\mathrm{Cu}$ content but also the graded film thickness were believed to be the main contributors to the much superior performance of the compositionally graded $\mathrm{SiCu}$ films. We also believe that the $\mathrm{Cu}$-rich region of the graded film helped reduce internal stress build-up and thus prevented film delamination during
\end{abstract}


cycling. In particular, the decrease of $\mathrm{Cu}$ content from interface region to the top of the coating reduced the possibility of stress build-up across the film during cycling, thus leading to a high electrochemical performance.

Keywords: Lithium ion batteries, anode, magnetron sputtering, $\mathrm{SiCu}$ thin film, gradedcomposition.

\section{Introduction}

Lithium is one of the most electropositive $(-3.04 \mathrm{~V}$ versus standard hydrogen electrode) and electrochemically active elements. This makes lithium ion batteries (LIB) more appealing than the other rechargeable batteries [1]. Even though there is an increasing interest in LIB, they are not the ultimate solutions for next generation battery technology. Because, the traditional carbon based anode materials (such as graphite, graphene, carbon nanotubes) are not able to meet the increasing demands for higher capacities and energy densities. There is a growing need for developing new electrode materials that can lead to a higher capacity for a longer cycle life.

To further improve the capacity of anode materials for LIB, silicon (Si) thin film has been considered as an ideal candidate with its high specific discharge capacity (3479 $\mathrm{mAh} \mathrm{g}^{-1}$, at room temperature) and low discharge potential. However, the short cycle life of Si thin film electrodes restrict its commercial use. There are three main reasons for this. First, when $\mathrm{Li}^{+}$diffuses into and intercalates with $\mathrm{Si}$ film, its volume expands by up to $400 \%$. Such a huge volume change causes the development of large internal stresses within the electrode leading to cracking, pulverization and delamination from the current collector, ultimately resulting in loss of electrical contact and eventual capacity fading. 
Second reason is its low electrical conductivity. Si retards the electrons' passage through the electrode thus causing lower capacity and quick failure. Third is the solid electrolyte interface (SEI) formation following the electrolyte reduction on the surface of $\mathrm{Si}$ electrodes. This has a negative effect on the cycle performance of Si-based thin film anodes. This SEI layer being ion conductive gets increasingly thicker during cycling which brings about a continuous decrease in capacity.

This short cycle life problem is currently being addressed by either forming buffering alloys with other ductile inactive elements or by using uniformly dispersed nano-sized inactive materials [2-4]. In this sense, $\mathrm{Cu}$ is used as an inactive material in various forms other than substrate or current collector [5-8]. However, the generation of the large stress difference due to volume expansion along the film could not be totally prevented by these approaches. To handle such a vital problem, strain-graded films have been produced by electron-beam evaporation having compositional grading or variation along the film thickness [9].

In this work, in an attempt to overcome the shortcomings mentioned above we designed and deposited a compositionally-graded thin film using the magnetron sputtering technique and compared its performance against the non-graded $\mathrm{SiCu}$. Impedance spectroscopy and cyclic voltammetry tests are applied at different cycles to gain an understanding of the electrochemical lithiation mechanism of the compositionally-graded electrodes. The proposed mechanism is justified by ex-situ SEM surface analysis results. Herein the magnetron sputtering is particularly chosen as it is used in the production of all kinds of other functional coatings. Furthermore, highly energetic sputtered ions and atoms of $\mathrm{Cu}$ and $\mathrm{Si}$ are expected to result in dense 
morphology across the coating and increase the adhesion of the deposited films to underlying substrates. In the first design (i.e., non-graded $\mathrm{SiCu}$ composite film), $\mathrm{Cu}$ and $\mathrm{Si}$ are co-deposited with a constant ratio (30/70 at. \%) throughout the coating to form a uniformly dispersed copper (and possibly copper silicides) in the anode. Copper is expected to help with the generation of an electron conductive network in the composite $\mathrm{Si}$ thin film. In the second design (i.e., compositionally graded composite film) $\mathrm{Cu}$ and $\mathrm{Si}$ are deposited to have the composition profile changing continuously from pure $\mathrm{Cu}$ (near the interface) to pure Si (near the surface) for minimizing stress-related degradation or spallation during cycling. Hypothetically, we believe that engineering a compositionally graded coating would promote the relief of stresses within the electrode and thus improve the adhesion of the film to the substrate without sacrifying the capacity delivered by the electrochemical cell.

\section{Experimental}

Non-graded and compositionally-graded $\mathrm{SiCu}$ films are produced using a CemeCon CC800/9 magnetron-sputtering system. The schematic representation of the experimental setup is given in Fig. 1. The substrates are cleaned with acetone and isopropyl alcohol before being placed into the coating chamber. The chamber is pumped

down to a base pressure of less than $10^{-5} \mathrm{~Pa}$. First, Ar etching is applied to the substrates at $-550 \mathrm{~V}$ bipolar pulses with $250 \mathrm{kHz}$ frequency and $1600 \mathrm{~ns}$ reverse time. In both cases the deposition for 120 minutes and $-100 \mathrm{~V}$ bias is applied (Fig. 1). For the non-graded composite films, $350 \mathrm{~W}$ and $2200 \mathrm{~W}$ are applied to $\mathrm{Cu}$ and $\mathrm{Si}$ targets, respectively. For the compositionally graded films, first 40 min constant power of $350 \mathrm{~W}$ is applied to $\mathrm{Cu}$ 
target, while the power applied to Si target is increased progressively at a rate of $25 \mathrm{~W}$ $\min ^{-1}$. Then, once the Si achieves $2200 \mathrm{~W}$, the power applied to $\mathrm{Cu}$ target is ceased to get pure Si film on top of the coating for the rest of the deposition (Fig. 1).

The films are deposited on four different substrates: Glass discs (Thermascal) for X-ray diffraction (XRD) analysis, Si wafers for cross sectional view, stainless steel discs (304, 15.5-mm diameter and 1.5-mm thickness) for compositional analysis and mechanically polished $(1200 \mathrm{~nm}, 800 \mathrm{~nm}, 600 \mathrm{~nm}, 320 \mathrm{~nm}, 3 \mu \mathrm{m}, 1 \mu \mathrm{m}, 0.5 \mu \mathrm{m}) \mathrm{Cu}$ discs (15.5-mm diameter and 1.5-mm thickness) for electrochemical experiments.

The amount of $\mathrm{Cu} / \mathrm{Si}$ atoms along the thin film thickness is monitored by glow discharge optical emission spectroscopy (GDOES) analysis (Jobin Ycon Horiba), where the RF excitation mode is used with $50 \mathrm{~W}$ power and $900 \mathrm{~Pa}$ pressure using the films coated on SS substrates. The surface morphology of the films before and after the cycle tests as well as the film thicknesses are investigated by field-emission scanning electron microscopy (FEG-SEM, JEOL JSM 7000F). To demonstrate the changes in film morphologies during cycling, the cells are discharged and subjected to 1, 3 and 60 cycles, then disassembled in the glove box. These cycled electrodes are then washed with DMC (dimethyl carbonate) and naturally dried in the glove box prior for ex-situ FEG-SEM.

The phases present in the coatings are determined using the Philips PW3710 XRD System with a $2 \theta$ range of $20-100^{\circ}$ in steps of $0.05^{\circ}$ (with $\mathrm{CuK} \alpha$ at $40 \mathrm{kV}$ and $30 \mathrm{~mA}$ ). Electrochemical performance of the non-graded and the compositionally-graded $\mathrm{SiCu}$ thin film electrodes is measured using a 2032 button coin cells, which are prepared in an Ar filled glove box (MBRAUN, Labmaster). The cell assembly is prepared in the following sequence: first the working electrode is placed on the lower cap of the cell, 
then the drops of electrolyte (i.e., $1 \mathrm{M} \mathrm{LiPF}_{6}$ in the ethylene carbonate-dimethyl carbonate form, (EC:DMC 1:1) (Merck Battery Grade)) is applied on the electrode surface, next the separator (Celgrad 2400), the lithium metal foil (as the counter electrode), the spring and the upper cap of the cell are all put on top of each other to complete the cell assembly. Once the cell is assembled in this manner, it is sealed by a pressure crimper inside a glove box. The galvanostatic tests are made at room temperature between $0.2-1.2 \mathrm{~V}\left(\mathrm{vs} \mathrm{Li} / \mathrm{Li}^{+}\right)$ with a rate of $\mathrm{C} / 12\left(100 \mathrm{~mA} \mathrm{~g}^{-1}\right)$.

Cyclic voltammetry $(\mathrm{CV})$ was performed for the $1^{\text {st }}, 2^{\text {nd }}, 3^{\text {rd }}$ and $60^{\text {th }}$ cycles in the potential range of $0.2 \mathrm{~V}-1.2 \mathrm{~V}\left(\mathrm{vs} \mathrm{Li} / \mathrm{Li}^{+}\right)$at a scan rate $0.03 \mathrm{mVs}^{-1}$. Electrochemical Impedance Spectroscopy (EIS) analyses are done on both pristine, $1^{\text {st }}, 3^{\text {rd }}$ and $60^{\text {th }}$ cycled samples in the frequency range of $10 \mathrm{mHz}-10 \mathrm{kHz}$ with $5 \mathrm{mV}$ rms at $0.2 \mathrm{~V}$ (Gamry PCI4/750) discharge potential. Finally, to evaluate the rate-capability of the compositionally graded $\mathrm{SiCu}$ film, series of galvanostatic tests with different rates are performed. The rate capability of the electrode is measured when the sample is charging with $100 \mathrm{mAg}^{-1}$ rate and discharging at different rates from 200 to $500 \mathrm{mAg}^{-1}$ (200, 300, and $500 \mathrm{mAg}^{-1}$ ). Both charging and discharging cycles are conducted between 1.2 and 0.2 $\mathrm{V}$ vs $\mathrm{Li} / \mathrm{Li}^{+}$. Since the discharge capacities at higher rates are lower than the charge capacity, 60 minutes open-circuit-potential relaxation is performed before the subsequent discharge reaction, as suggested by Sethuraman et al [10]. This enables that the electrode retains its low state-of-charge before the beginning of each rate experiment.

In order to obtain detailed understanding of the interactions between $\mathrm{Cu}$ and $\mathrm{Si}$ phases in the presence of $\mathrm{Li}$, first $\mathrm{Cu}-\mathrm{Si}$ phase diagram should be considered in details [11]. As shown in the phase diagram in Fig. $1 \mathrm{~b}$, when $\mathrm{Cu}$ and $\mathrm{Si}$ are mixed, various 
intermetallics such as $\mathrm{Cu}_{3} \mathrm{Si}, \mathrm{Cu}_{5} \mathrm{Si}, \mathrm{Cu}_{33} \mathrm{Si}_{17}, \mathrm{Cu}_{19} \mathrm{Si}_{6}$ may form. These intermetallics have different crystalline structures (like tetragonal, bcc, hcp etc). Therefore, they might have different electrochemical behaviors.. In fact, several research groups have already published articles about the uses of $\mathrm{Cu}_{5} \mathrm{Si}$ [12-13] and $\mathrm{Cu}_{3} \mathrm{Si}$ [14] as more effective anode materials for lithium ion batteries. They indicated that $\mathrm{Cu}_{5} \mathrm{Si}$ behaves inactively against $\mathrm{Li}$, but $\mathrm{Cu}_{3} \mathrm{Si}$ have a complex lithiation mechanism with $\mathrm{Li}$. In our paper, we will provide a detailed explanation about the relationship between different crystalline phases (or structures) and their electrochemical performance as potential anode materials in the following section.

\section{Results and Discussions}

The surface and the cross sectional SEM images of the non-graded and the compositionally graded $\mathrm{SiCu}$ films are shown in Figs. 2a-d. From the top view, a homogenous morphology is noticed for both films (Figs. 2b,d). In the case of non-graded $\mathrm{SiCu}$ film, one can notice a much finer grainy surface morphology. This is most likely due to the co-deposition of $\mathrm{Cu}$ and $\mathrm{Si}$ atoms preventing agglomeration or separation of $\mathrm{Si}$ phase or grain into large domains. On the other hand, the compositionally graded film displays a coarser surface morphology and grain size. The deposition of $\mathrm{Si}$ atoms on the top of the coating might have caused such coarsening or agglomeration, thus leading to crack formation mainly because of increasing internal stress near the top (which was pure $\mathrm{Si}$ or $\mathrm{Si}$ rich). The cross sectional images show that both films have a thickness around 3 $\mu \mathrm{m}$ (Figs. 2a-c). EDS analyses reveal the presence of 31.7 at. $\%$ and 34.2 at. $\% \mathrm{Cu}$ in the non-graded and the compositionally graded composite films, respectively. The oxygen 
and argon content of the films are also noted to be less than 5 at. \% from the EDS analysis.

Non quantitative GDOES depth profile results are given in Figures 3a-b. As seen in Figure 3a the non-graded film reveals a fairly constant $\mathrm{Cu} / \mathrm{Si}$ ratio across the film thickness. This is very different from the compositionally graded film as shown in Figure $3 \mathrm{~b}$, which exhibits that the amount of $\mathrm{Si}$ along the film thickness is increased from the bottom to the top. However, the amount of $\mathrm{Cu}$ present along the film thickness is fairly constant in the first micrometer, but then decreases precipitously as the film thickens but the Si keeps increasing and stabilizing after about $2 \mu \mathrm{m}$. Thus, the top $1 \mu \mathrm{m}$ of the film is essentially made of Si. In short, the resulting film is made of pure $\mathrm{Si}$ atoms at the top and pure $\mathrm{Cu}$ atoms at the bottom. The backscattered SEM view given in Figure 3c also justifies the distributions of $\mathrm{Cu}$ and $\mathrm{Si}$ atoms along the film thickness. The bright appearance shows the existence of $\mathrm{Cu}$ atoms in the coating. The existences of $\mathrm{Cu}$ rich, transition and Si rich zones are clearly seen from the bottom to the top of the deposit.

The structural properties of the films are further investigated by means of XRD (Fig. 4a), which is taken from the films coated on the glass discs. Since the XRD diffractogram for glass substrate shows amorphous structure this will not interfere with the XRD analyses of the SiCu film on top (Fig. 4b). Fig. 4a shows that both films contain crystalline $\mathrm{Cu}_{3} \mathrm{Si}$ intermetallic phase (JCPDS:00-051-0916). Moreover, the bump at low diffraction angle also proves the prevalence of amorphous particles in the graded composition compared to the non-graded one.

The compositions of the coatings are analyzed considering the area under the peaks on the normalized XRD spectrum. The results justify that the non-graded film 
contains higher amounts of $\mathrm{Cu}_{3} \mathrm{Si}$ atoms because the area under the peak $2 \theta=44.977^{0}$ is much greater than the one of the non-graded electrode. In addition, $\mathrm{Cu}_{3} \mathrm{Si}$ particles could be in a nanocrystalline state in this graded film since the FWHM of the peak at 44.977 is different for both samples.

The reversible reaction of $\mathrm{Cu}_{3} \mathrm{Si}$ with $\mathrm{Li}$ and its high electronic conductivity are expected to promote superior electronic conductivity (thus minimizing electrochemical agglomeration of Si particles) and thus suppress volume changes in the anode [15]. The reaction mechanism of $\mathrm{Cu}_{3} \mathrm{Si}$ with $\mathrm{Li}$ has been described previously [15-16]. During lithiation, the elemental $\mathrm{Cu}$ is ejected from the $\mathrm{Cu}_{3} \mathrm{Si}$ crystal and would act as a buffering matrix to minimize the destroying effect of the volume changes caused by $\mathrm{Li}_{\mathrm{x}} \mathrm{Si}$ formation (Equation 1). This lithiated Si product surrounded by the conductive $\mathrm{Cu}$ matrix enhances the reversibility of the charge/discharge reactions, which intensifies the cycle stability of the thin film electrode, eventually (see Equation 1).

$x \mathrm{Li}^{+}+\mathrm{xe}^{-}+\mathrm{Cu}_{3} \mathrm{Si} \rightarrow \mathrm{Li}_{x} \mathrm{Si}+3 \mathrm{Cu} \rightarrow 3 \mathrm{Cu}+\mathrm{Si}+\mathrm{xLi}^{+}+\mathrm{xe}^{-}$

(Equation1)

The absence of $\mathrm{Cu}$ and $\mathrm{Si}$ crystal peaks justifies the presence of $\mathrm{Cu}$ and $\mathrm{Si}$ particles as amorphous/nanocrystalline states in both coatings. In previous studies, $\mathrm{Li}^{+}$ insertion/extraction mechanisms in Si are analyzed by using in-situ XRD, SEM and high resolution transmission electron microscopy methods (HR-TEM) [17-20]. In Refs 17-20, it is reported that in compliance with the "solid-state amorphization theory", during $\mathrm{Li}^{+}$ insertion, the crystal structure of the nano-sized Si particle is destroyed and converted into an amorphous metastable structure ( $\mathrm{Li}-\mathrm{Si})$ without formation of intermediate phases. This amorphous lithiated Si phase prevails up to $0.05 \mathrm{~V}$ followed by the formation of a new crystalline $\left(\mathrm{Li}_{15} \mathrm{Si}_{4}\right)$ compound when the cell potential goes down to values below 
0.05V. Furthermore, studies point out that during $\mathrm{Li}^{+}$extraction (on the anodic side), crystalline $\mathrm{Li}_{15} \mathrm{Si}_{4}$ is converted into two different phases (amorphous and crystalline), where $\mathrm{Li}^{+}$ions are trapped resulting in a decrease in the specific capacity delivered by the electrodes. Therefore, to eliminate irreversible lithiation reactions and to optimize the volume expansion in the anode, the lower cut off potential of the galvanostatic test is fixed at $0.2 \mathrm{~V}$. In addition, the lithiation mechanism of amorphous $\mathrm{Si}(\mathrm{a}-\mathrm{Si}$ ) is also investigated by those researches in Refs. 13-16. The results prove that there is no additional recrystallization occurring during the lithiation reaction of a-Si. Therefore, more stable cycle performance would be achieved by using a-Si as an anode material.

The $\mathrm{Li}^{+}$insertion/removal mechanisms for the non-graded and the graded $\mathrm{SiCu}$ films are investigated by $\mathrm{CV}$ test, for the $1^{\text {st }}, 2^{\text {nd }}, 3^{\text {rd }}$ and $60^{\text {th }}$ cycles (Figs. 5a-b). The voltage-capacity plots of both samples are also given on the upper-right sides of $\mathrm{CV}$ curvatures. Capacity-voltage curves show that both samples have a similar lithiation mechanism than that of the pure $\mathrm{Si}$ electrode (not shown here), which confirms the electrochemically inactive behavior of $\mathrm{Cu}$ atoms versus $\mathrm{Li}^{+}$. A passive film forms on both electrodes' surfaces following the electrolyte reduction as seen by small plateau around $1.5 \mathrm{~V}$ in the first cycle. Afterwards, a large plateau is detected around $0.2 \mathrm{~V}$ showing the reaction of $\mathrm{Si}$ with $\mathrm{Li}$. When the $\mathrm{CV}$ curves are observed, Figure 5a shows one remarkable cathodic (around $0.2 \mathrm{~V}$ ) and anodic (around $0.6 \mathrm{~V}$ ) peaks of which intensities decrease in following cycles suggesting possible solid electrolyte interface (SEI) formation and delamination in galvanostatic test. Figure $5 \mathrm{~b}$ shows that the graded film has a high capacitance initially. The large Si particles on the surface of the electrode might be a reason for this. Then, at $60^{\text {th }}$ cycles, the curvature shape becomes very close to 
the non-graded film, which has $\mathrm{Cu}$ atoms along the film resulting in small particle sizes. This proves that the surface morphology of the graded electrode changes in galvanostatic test.

Figs. 6 a-b show the charge/discharge cycling data for both the non-graded and graded electrodes. The non-graded film performs $1100 \mathrm{mAh} \mathrm{g}^{-1}$ as the initial discharge capacity with $78 \%$ coulombic efficiency. The capacity-cycle diagram shows that the amount of capacity delivered by the anode in $100^{\text {th }}$ cycles decreases gradually and stabilizes at $250 \mathrm{mAh} \mathrm{g}^{-1}$ with $98 \%$ coulombic efficiency. Such a dramatic failure may occur due to a significant loss of electrical contact between the coating and the current collector. It is believed that beside the continuous SEI formation, cracks and/or some delamination are formed during the first cycle, then such cracks and delamination propagate and become more prominent when cycling continues, resulting in a continuous decay of capacity.

On the other hand, the capacity-cycle diagram of graded-composition $\mathrm{SiCu}$ film shows $1400 \mathrm{mAhg}^{-1}$ as the first discharge capacity with $80 \%$ coulombic efficiency. The first discharge value of the electrode is low compared to the theoretical capacity. Morphological restrictions of the film (the coating has large particle sizes as seen in Figure $2 b, d)$ might limit the access of lithium to the active materials present in the electrode. This outcome is in good agreement with CV results where a very high capacitance effect is obviously seen in the initial cycles. Note that the capacity delivered by the electrode increases in following cycles and attains a value of $2100 \mathrm{mAh} \mathrm{g}^{-1}$ with $98 \%$ coulombic efficiency. Possible pulverization and small size crack formation in the coating resulting exposure of the fresh active material ( $\mathrm{Si}$ or $\mathrm{Cu}_{3} \mathrm{Si}$ particles in that case) 
to $\mathrm{Li}^{+}$could explain this increase in capacity. However, after 14 cycles the capacity decreases again because the passive film formation prevails on those freshly exposed active particles surfaces following the electrolyte reduction reactions. This change in the capacity would be better analyzed (in Fig. 6b) in two parts: from $1^{\text {st }}$ to $50^{\text {th }}$ cycle a fluctuation is noted, then after $50^{\text {th }}$ cycles the capacity becomes stable around $600 \mathrm{mAhg}^{-}$ ${ }^{1}$ with $99.9 \%$ coulombic efficiency. So far in literature, for such a thick film electrode, this abrupt stabilization in the capacity has not been reported. Particularity in the composition and the structure of the coating would explain this peculiar behavior of the compositionally graded $\mathrm{SiCu}$ film. Indeed, this fluctuation noted in the first 50 cycles could be explained regarding the compressive and tensile stresses that the electrode undergoes during cycling leading to a partial pulverization and small crack formation in the coating. As opposed to the non-graded electrodes that suffer severe delamination during cycling, the graded electrodes divert the propagation of the stresses along the film and increases the adhesion of the coating to the current collector resulting in higher cycle life and better performance.

The EIS spectra (see Figs 7 a and b) are explained based on the equivalent circuit model given in Fig. $7 c$, where $R_{s}$ is used as uncompensated ohmic resistance, $R_{f}$ as surface resistance of the electrode, $\mathrm{CPE}_{\mathrm{f}}$ as constant phase element of the coatings with the electrolyte interface and $\mathrm{W}_{\mathrm{c}}$ as the Warburg element which describes the solid state diffusion inside the coatings. Here, we use the constant phase element (CPE) instead of capacitance because the films are not continuous and the size of particles is distributed around an average value. Note that CPE is not only the double layer capacitance at the interface but also includes lithium intercalation capacitance in the active materials. The 
solid line and the square dots seen in Figs. 7a-b are the results of experiments and according to the curve fitting data from the model, respectively. This proves that the model fits quite well with the experimental EIS spectrum.

When the Nyquist plots of the pristine electrode are analyzed, it is seen that at higher frequencies (around $10 \mathrm{kHz}$ ), the spectrum of the compositionally graded electrode displays a very low and stable uncompensated resistance values $\left(\mathrm{R}_{\mathrm{s}}\right.$, around $5 \Omega$ ). Knowing that $10 \mathrm{kHz}$ is a low frequency value to get any inductive distortion in the spectra, the resistance seen in Figs. $7 \mathrm{a}-\mathrm{b}$ around $10 \mathrm{kHz}$ is a pure resistive behavior $\left(\mathrm{Z}_{\mathrm{im}}\right.$ close to 0 ). This low uncompensated resistance value is stable even at $60^{\text {th }}$ cycle for the compositionally graded film demonstrating that the stress relief in the electrode is wellachieved by designing a composite film rich in $\mathrm{Cu}$ at the bottom and $\mathrm{Si}$ on the top. This design promotes the connection between the substrate and the coating, avoiding any delamination during cycling while taking advantage of the Si atoms on the top. On the other hand, for the non-graded film the uncompensated resistance value increases progressively after the $1^{\text {st }}$ discharge reaction. This increase in $R_{s}$ value becomes remarkable in $3^{\text {rd }}$ and $60^{\text {th }}$ cycles. This demonstrates that after the $1^{\text {st }}$ cycle severe cracks with delamination form in the non-graded coating increasing the resistance between the substrate and the active material.

In case of lower frequencies $(10 \mathrm{kHz}-10 \mathrm{~Hz})$, the effect of the surface resistance in parallel with the capacitance is seen as a depressed semi-circle in Figs 7a-b. Each active component of the electrode contributes to the surface resistance due to both the SEI passive film and the electron transfer resistances preventing direct electron transfer during cycling. For the non-graded film, a remarkable increase in $\mathrm{R}_{\mathrm{f}}$ values is noted after 
$3^{\text {rd }}$ cycles. This could be attributed to the growth in SEI film and the volume expansion of active materials that block the $\mathrm{Li}$ movement in the electrode causing generation and prevalence of delamination. While the graded electrode's EIS spectra is observed, the $R_{\mathrm{f}}$ values seem to be much higher than that of the non-graded electrode. This is in agreement with the CV results where a very high capacitance effect is noted in the initial three cycles causing high charge transfer resistance. Large particle size restricting the access of $\mathrm{Li}^{+}$in the coating and the poor electric conductivity of $\mathrm{Si}$ on the top layer might explain this high charge transfer impedance value. However, when the changes in $R_{f}$ values are observed a progressive decrease is noted during the galvanostatic test. The changes in film morphology following the volumetric changes occurred in the electrode could elucidate this decrease. As this graded film (rich in $\mathrm{Cu}$ at the bottom) is well adhered to the $\mathrm{Cu}$ substrate the changes in stress along the electrode causes pulverization of the particles (without delamination from the current collector) exposing fresh active materials $\left(\mathrm{Cu}_{3} \mathrm{Si}\right.$ and $\mathrm{Si}$ particles in that case) to $\mathrm{Li}^{+}$which would be also passivated following the electrolyte reduction in following cycles.

At lower frequencies (below 10Hz), an upward slope so called Warburg impedance tails observed for each sample. The Warburg tail accounts for diffusion limitations in the electrode, which includes diffusion through the electrolyte, the electrode surface layers, and the active particles. Fig. 7a shows that $\mathrm{Li}^{+}$can diffuse in the electrode during the galvanostatic test through cracks formed following the $1^{\text {st }}$ discharge reaction. As cycling proceeds SEI formation and delamination of the coating become more prominent causing changes in $\mathrm{Li}^{+}$diffusion kinetic as seen by the deviation of the slope (Warburg tail) from $45^{0}$ after $60^{\text {th }}$ cycles. On the other hand, for the graded- 
composition film, the Warburg tail becomes more remarkable and gets closer to $45^{\circ}$ during cycling. This shows that the change in the film morphology would facilitate $\mathrm{Li}^{+}$ diffusion along the film, resulting a stable, high electrochemical performance in cycling test after $50^{\text {th }}$ cycle.

Knowing that high impedance diminishes the cell ability to deliver and accept current pulses at relatively high rate, the rate test is only applied on the graded electrode (Fig. 8). The result of the rate-capability test is in well agreement with the above mentioned lithiation mechanism. Fig. 8 shows that once the cycle rate is increased from 200 to $500 \mathrm{mAg}^{-1}$, the amount of capacity delivered by the anode is decreased. Moreover, the graph shows that with an increase in the cycle rate, the coulombic efficiency increases as well. Herein, the fact that the sample delivers roughly $500 \mathrm{mAh} \mathrm{g}^{-1}$ discharge capacity at different cycling rates (i.e., 200, 300, $500 \mathrm{mAg}^{-1}$ rate) proves the enhanced capability of the electrode to withstand high cycle rates $\left(500 \mathrm{mAg}^{-1}\right)$. The improved stress relief behavior of the graded film is a good reason to explain this.

The SEM views of the samples after the $1^{\text {st }}$ discharge, $1^{\text {st }}$ charge, $3^{\text {rd }}$ and $60^{\text {th }}$ cycles (Figs. 9a-b) support the above-mentioned explanation. After the first charge reaction, no cracks are detected on the SEM images of both samples. Only the particles are swollen without major cracks or delamination. However, after the very $1^{\text {st }}$ discharge reaction delamination is noted in the non-graded electrode whereas pulverization is detected on the graded film surface. After the $3^{\text {rd }}$ cycle, delamination and large cracks become more prominent on the non-graded electrode. However, a remarkable pulverization is detected in the graded film but no evidence of delamination was observed. After $60^{\text {th }}$ cycles, changes in the film morphology become more pronounced. 
The non-graded film is severely delaminated and reduced to isolated islands with large interspaces between them but the graded film is still attached to the substrate surface with significant pulverization. Overall, the results from these ex-situ surface/structural analyses are in well agreement with the comparative electrochemical outcomes of both SiCu films.

\section{Conclusions}

To improve the electrochemical performance of the Si anode, the non-graded and the compositionally graded $\mathrm{SiCu}$ films are produced by a simple, scalable, and versatile method; magnetron sputtering. Their potential uses as more durable anode materials in LIB are explored and the summary of our findings is provided below:

- In case of thin film electrodes, common understanding is that an increase in film thickness causes quick failure of the electrodes. However, our study confirms that by an accurate selection of constituent materials (i.e., $\mathrm{Cu}$ and $\mathrm{Si}$ ) and by strategic structural design (i.e., compositionally graded $\mathrm{Cu}$ rich at bottom and $\mathrm{Si}$ rich on top); resultant electrodes having $3 \mu \mathrm{m}$ total film thickness can deliver $600 \mathrm{mAh} \mathrm{g}^{-1}$ with $99.9 \%$ Coulombic efficiency at $100^{\text {th }}$ cycle.

- This work reveals the advantages of using a compositionally graded film as the more effective anode material for LIB applications. The gradient film has a composition profile that changes continuously from pure $\mathrm{Cu}$ to pure $\mathrm{Si}$ along the film thickness. The existence of $\mathrm{Cu}$ atoms in the coating is believed to hinder crack initiation and propogation and eventual total failure of the electrodes mainly becuase of the enhanced adhesion and better ability to accomodate stress build-up during cyling. Moreover, the co-existence of 
highly energetic $\mathrm{Cu}$ and $\mathrm{Si}$ in the coating promotes intermetallic $\mathrm{Cu}_{3} \mathrm{Si}$ formation in the electrode which enhances reversibility during lithiation.

- The Coulombic rate test proves that by designing a compositionally graded $3 \mu \mathrm{m}$ thick $\mathrm{SiCu}$ film, it is possible to produce a highly functional $\mathrm{Si}$ based electrode delivering 500 $\mathrm{mAhg}^{-}$capacity at high cycle rates $\left(500 \mathrm{mAg}^{-}\right)$without failure or delamination.

- The impedance evolution of the electrodes during cycling suggests that growth of SEI, evolution of stres along the film and the interaction of the coating with the substrate are mainly responsible for the cycling performances of the electrodes.

- Overall, in this study, we provided a much clearer understanding of the relationship between compositional, structural nature and electrochemical performance of the thin film-based electrodes. It is hoped that our findings will increase the likelihood of making high capacity Si-based anodes for use in next generation LIBs.

\section{Acknowledgement}

The authors thank Prof. Dr. Gültekin Göller, Prof. Dr. Mustafa Ürgen Prof. Dr. Servet Timur, Hüseyin Sezer, Sevgin Türkeli and Kübra Yumakgil for their valuable helps for SEM, XRD and CV analyses. Work at Argonne National Laboratory was supported by the U.S. Department of Energy, Office of Energy Efficiency and Renewable Energy, under Contract DE-AC02-06CH11357.

\section{References}


1. R. Teki, M.K. Datta, R. Krishnan, T.C. Parker, T.-M. Lu, P.N. Kumta, N. Krotkar Nanostructured silicon anodes for lithium ion rechargeable batteries, Small 5 (2009) $2236-2242$

2. K. Guo, Q. Pan, L. Wang, S. Fang, Nano-scale copper-coated graphite as anode material for lithium-ion batteries, J. Appl. Electrochem. 32 (2002) 679-685.

3. J. Gao, H.P. Zhang, T. Zhang, Y.P. Wu, R. Holze, Preparation of Cu coating on graphite electrode foil and its suppressive effect on PC decomposition, Solid State Ionics 178 (2007) 1225-1229

4. J.W. Kim, J.H. Ryu, K.T. Lee, S.M. Oh, Improvement of silicon powder negative electrodes by copper electroless deposition for lithium secondary batteries, J. Power Sources 147 (2005) 227-233

5. W. Pu, X. He, J. Ren, C. Wan, C. Jiang, Electrodeposition of Sn-Cu alloy anodes for lithium batteries, Electrochim.Acta 50 (2005) 4140-4145.

6. J. Gao, L.J. Fu, H.P. Zhang, T. Zhang, Y.P. Wu, H.Q. Wu, Suppression of PC decomposition at the surface of graphitic Carbon by $\mathrm{Cu}$ coating, Electrochem. Comm. 8 (2006) 1726-1730.

7. K. Guo, Q. Pan, L. Wang, S. Fang, Nano-scale copper-coated graphite as anode material for lithium-ion batteries, J. Appl. Electrochem. 32 (2002) 679-685.

8. Y.P. Wu, R. Holze, Preparation of $\mathrm{Cu}$ coating on graphite electrode foil and its suppressive effect on PC decomposition, Solid State Ionics 178 (2007) 1225-1229

9. Y.He, J. Fan, Y.Zhao, Engineering a Well-Aligned Composition-Graded CuSiNanorod Array by an Oblique Angle Codeposition Technique, Cryst. Growth Des. 10 (2010) 4954-4958. 
10. V. A. Sethuraman, K. Kowolik, V. Srinivasan, Increased cycling efficiency and rate capability of copper coated silicon anodes in lithium ion batteries, J. Power Sources 196 (2011) 393-398.

11. Binary Alloy Phase Diagrams, Second Edition, Ed. T.B. Massalski, ASM International, Materials Park, Ohio (1990) 2, 1477-1478

12. P.Wang, Y. NuLi, J. Yang, Y. Zheng, Carbon-coated Si-Cu/graphite composite as anode material for lithium-ion batteries, Int. J. Electrochem. Sci, 1 (2006) 122-129

13. Y. NuLi, B. Wang, J. Yang, X. Yuan, Z.Ma, $\mathrm{Cu}_{5} \mathrm{Si}-\mathrm{Si} / \mathrm{C}$ composites for lithium-ion battery anodes J. Power Sources 153 (2006) 371-374

14. M. Au, Y. He, Y.Zhao, H. Ghassemi, R.S.Yassar, B.G.-Diaz, T.Adams,Silicon and silicon-copper composite nanorods for anodes of Li-ion rechargeable batteries, J. Power Sources 196 (2011) 9640-9647

15. S. Murugesan, J.T. Harris, B.A. Korgel, K.J. Stevenson, Copper coated amorphous silicon particles as anode material for lithium ion batteries, Chem. Mater. 24 (2012) 1306-1315

16. N.G. Semaltianos, Thermally evaporated aluminum thin films, Appl. Surf.Sci. 183 (2001) 223-229

17. U. Kasavajjula, C. Wang, A.J. Appleby, Nano- and bulk-silicon-based insertion anodes for lithium-ion secondary cells, J. Power Sources 163 (2007) 1003-1039.

18. S. Young, D.-T. Shieh, H.-C. Wu, M.-H. Yang, N.-L. Wu, Effect of electrode structure on performance of $\mathrm{Si}$ anode in Li-ion batteries: Si particle size and conductive additive, J. Power Sources 140 (2005) 139-144. 
19. P. Limthongkul, Y.-II. Jang, N. J. Dudney, Y.-M.Chiang, Electrochemically-driven solidstate amorphization in lithium-metal anodes, J. Power Sources 119 (2003) 604-609.

20. P. Limthongkul, Y.-II. Jang, N.J. Dudney and Y.-M.Chiang, Electrochemically-driven solid-state amorphization in lithium-silicon alloys and implications for lithium storage, Acta Mater.51 (2003) 1103-1113 


\section{Figure Captions}

Figure 1. a) Experimental Setup for magnetron sputtering, b) $\mathrm{Cu}-\mathrm{Si}$ phase diagram

Figure 2. SEM surface and cross sectional views of the non-graded film $(a, b)$ and the compositionally graded film (c,d)

Figure 3. GDOES analyses of a) the non-graded and b) graded $\mathrm{SiCu}$ film, c) Backscattered SEM view of the graded $\mathrm{SiCu}$ film.

Figure 4.a) XRD spectra of the non-graded and graded SiCu films, b) XRD spectrum of the substrate material.

Figure 5. CV test results of a) non-graded film, b) graded film for the $1^{\text {st }}, 2^{\text {nd }}, 3^{\text {rd }}$, and $60^{\text {th }}$ cycles (right-up side voltage-capacity plots are also given).

Figure 6. Capacity-cycle plots of a) the non-graded, b) the composition-graded $\mathrm{SiCu}$ thin films.

Figure 7. EIS test results of a) the non-graded, b) the graded composition films at $0.2 \mathrm{~V}$ for the pristine, $1^{\text {st }}, 3^{\text {rd }}$ and $60^{\text {th }}$ cycles, c) Schematic representation of the model to explain EIS data.

Figure 8. Rate test result of the graded $\mathrm{SiCu}$ thin film anode

Figure 9.SEM surface views of the graded and the non-graded films after $1^{\text {st }}$ discharge, $1^{\text {st }}$ cycle, $3^{\text {rd }}$ and $60^{\text {th }}$ cycles. 


\section{Graded SiCu Film}

\section{Composite SiCu Film}

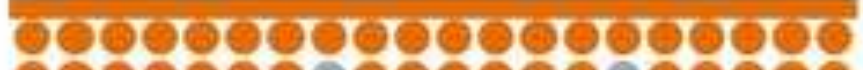
-

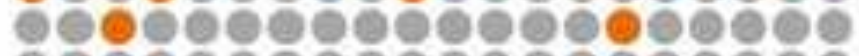

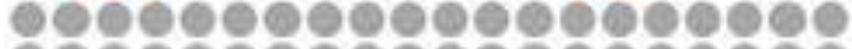

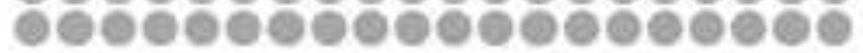

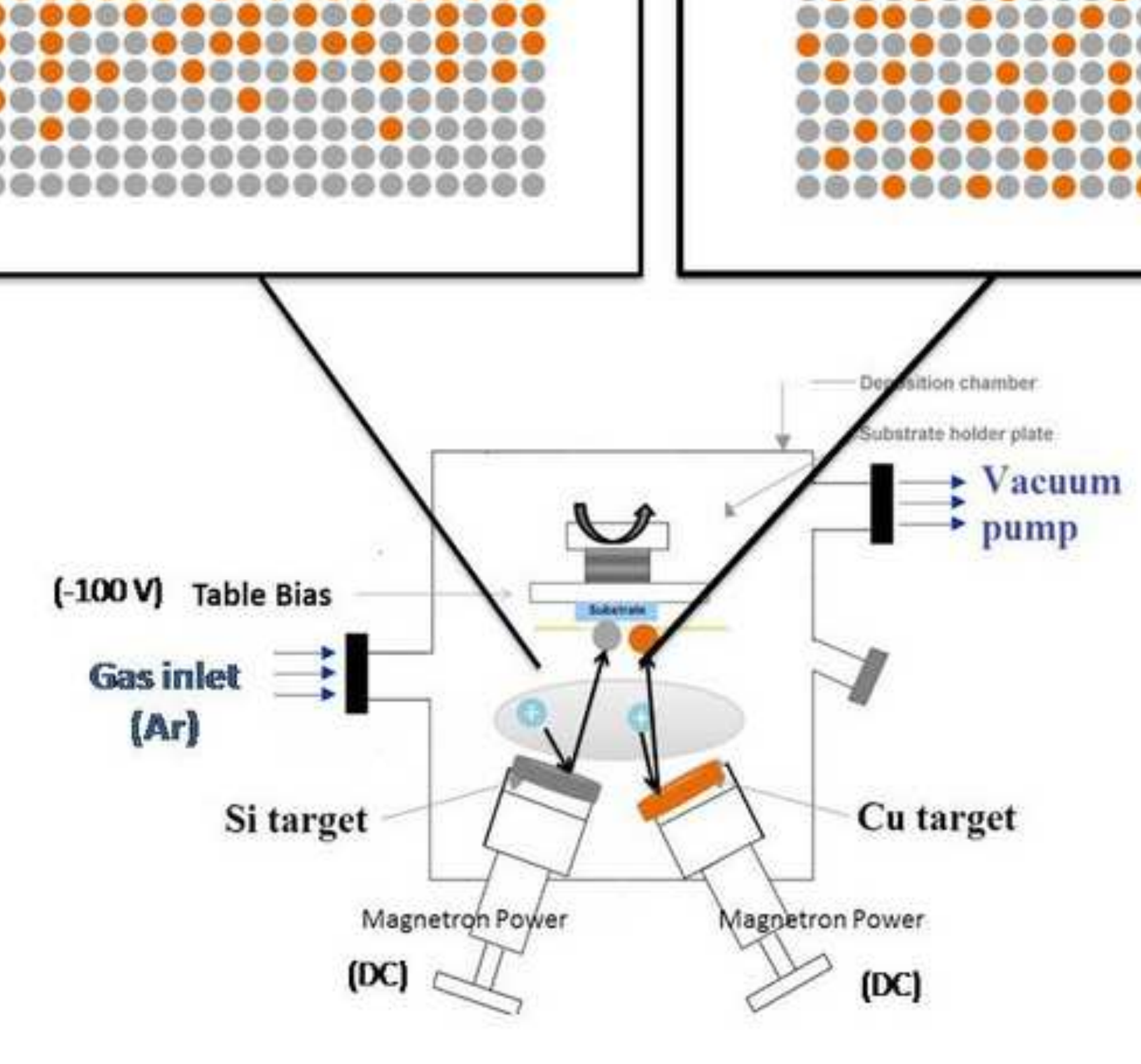

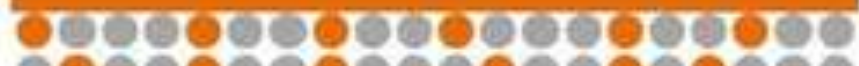
(2)을

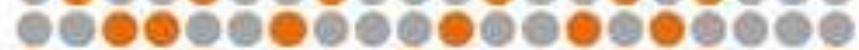

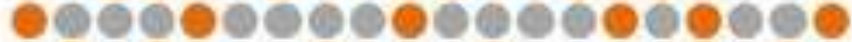

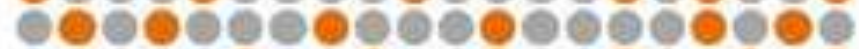

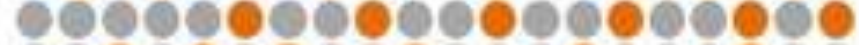

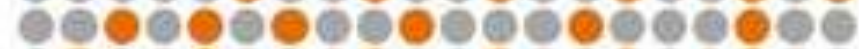

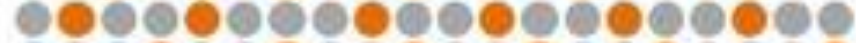

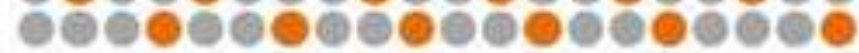

.

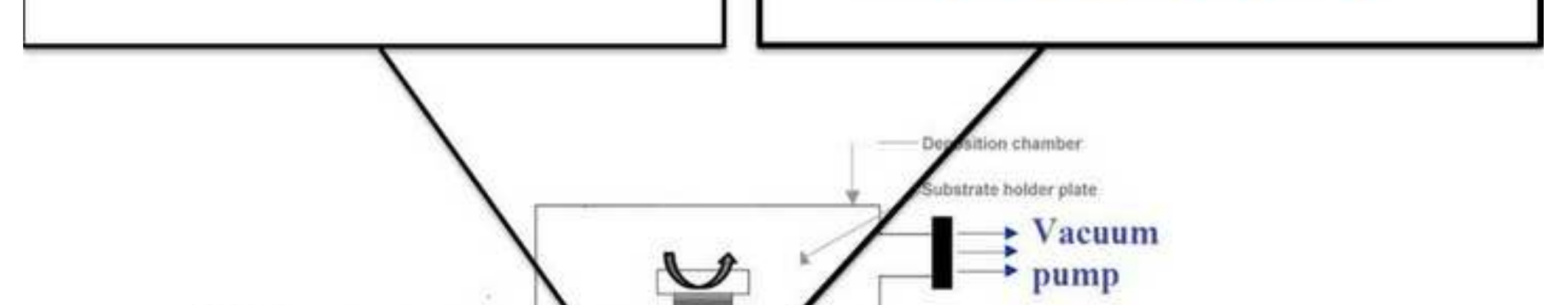




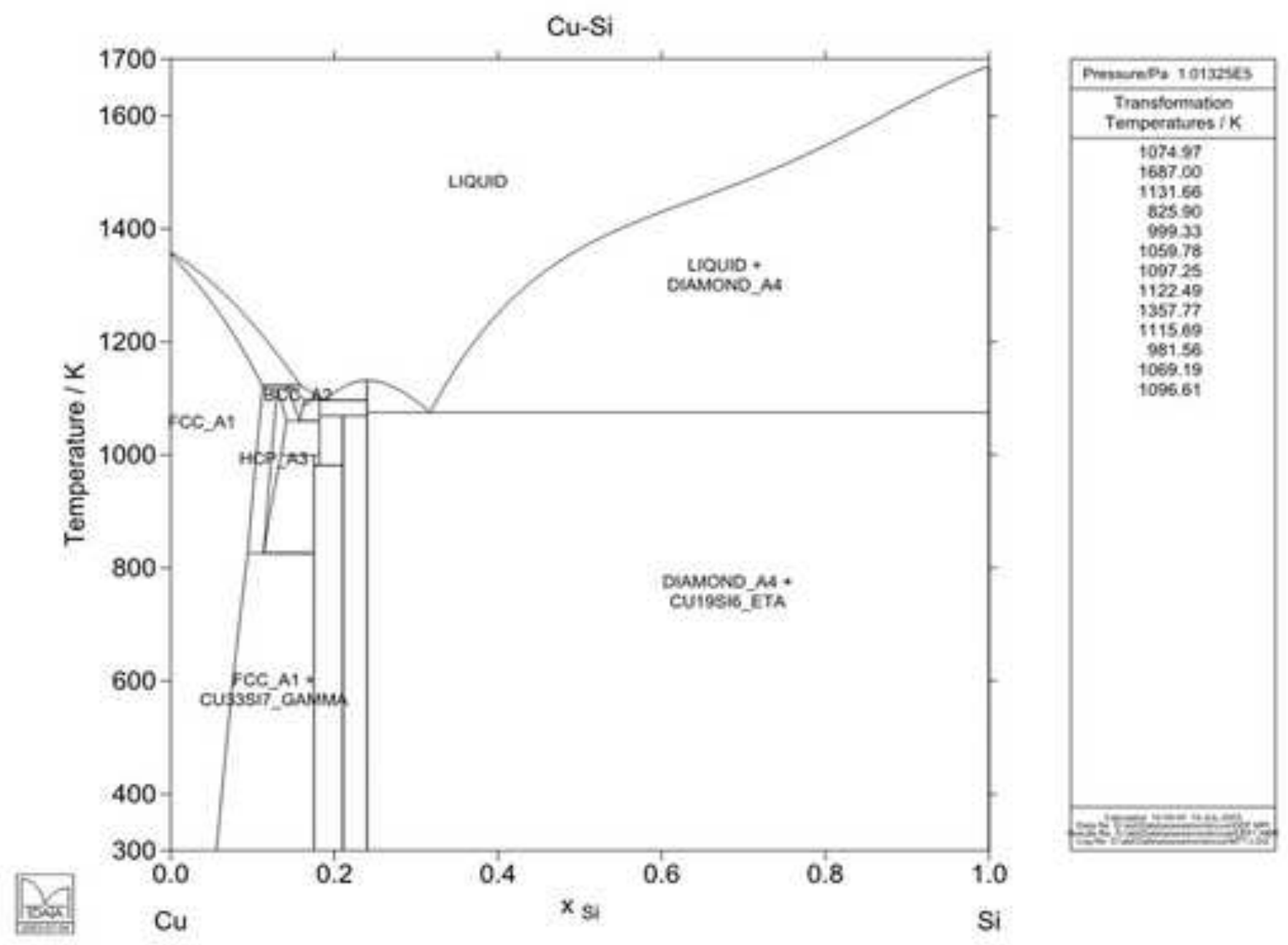




\section{a)}

c)
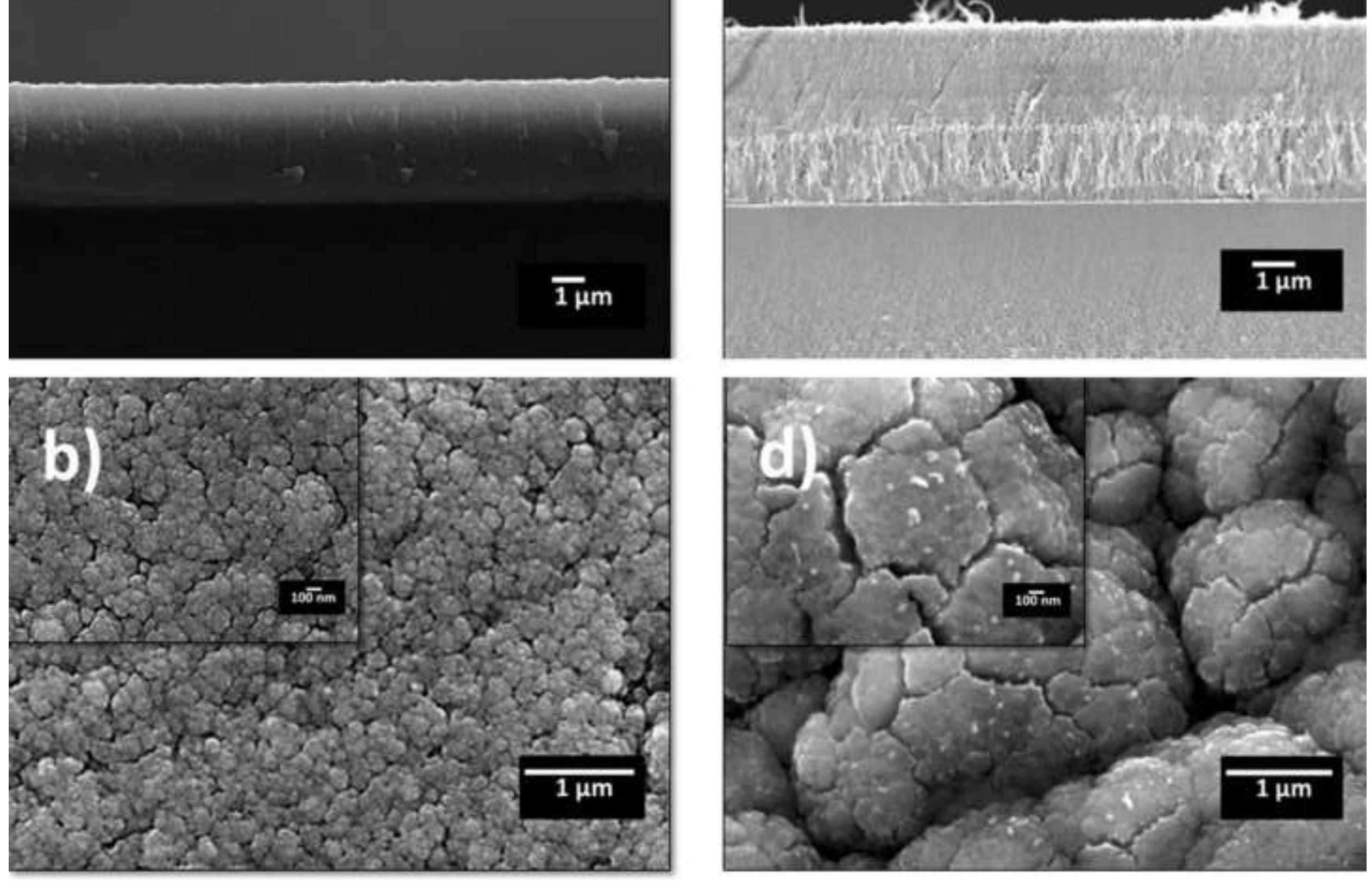

$\overline{1 \mu m}$ 


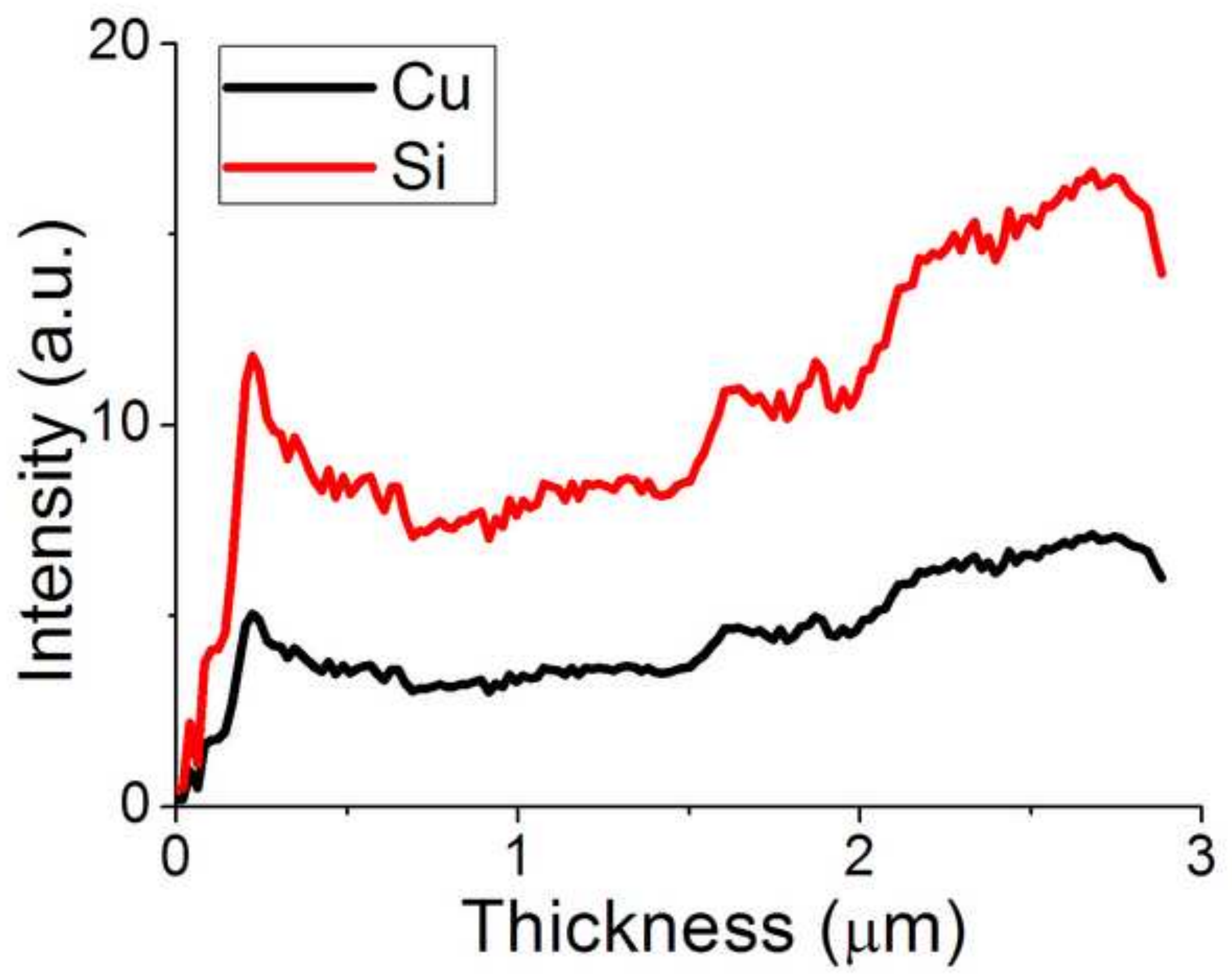




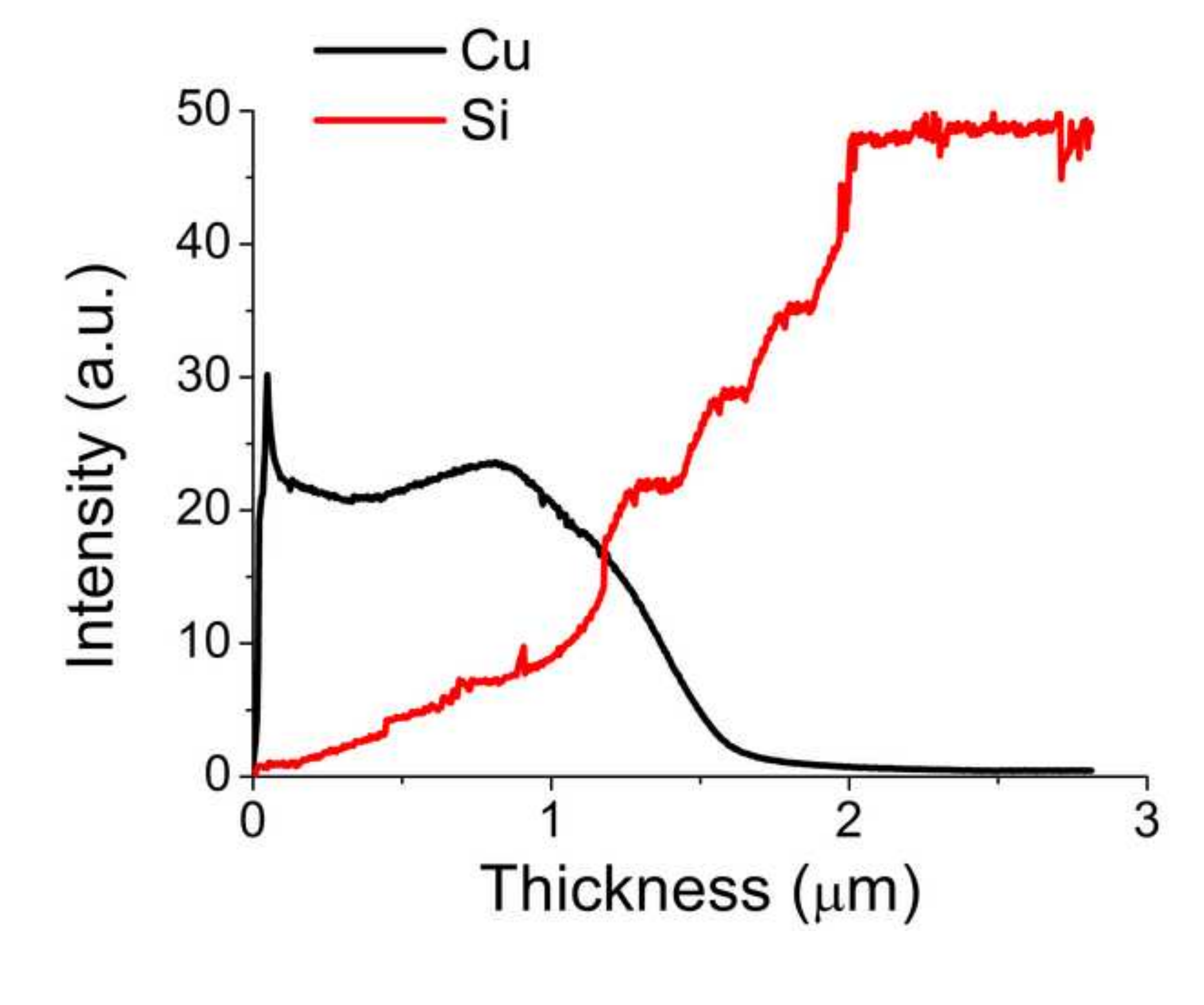

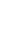

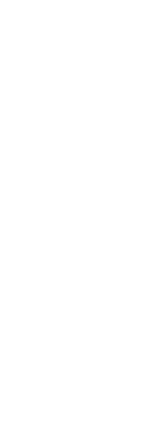
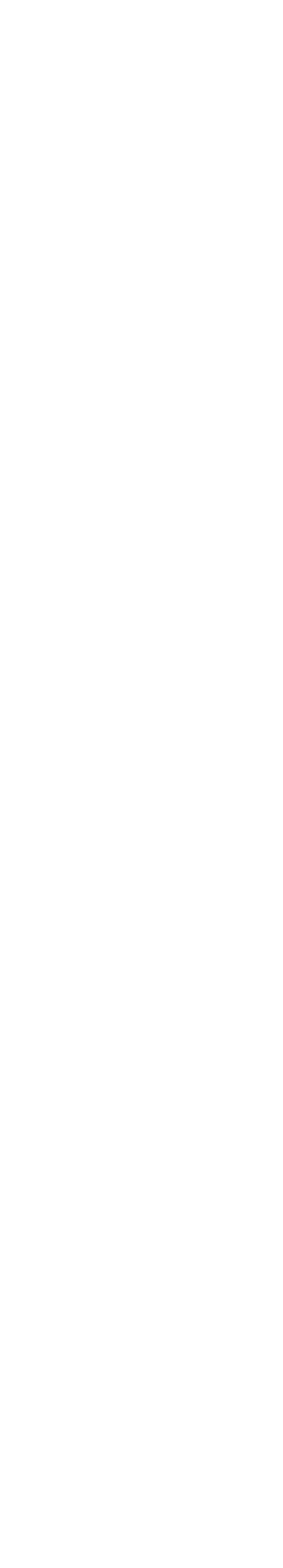

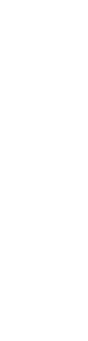




\title{
Pure Si
}

Transition zone from rich in Cu to puresi

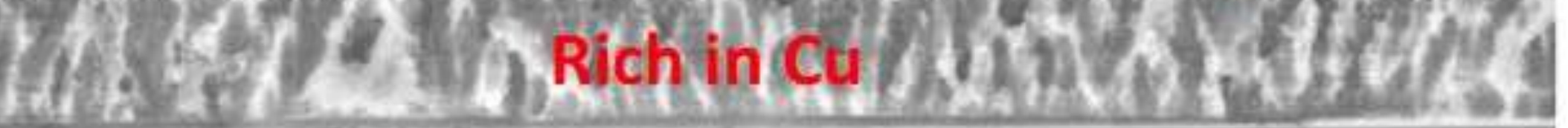

\author{
Substrate
}

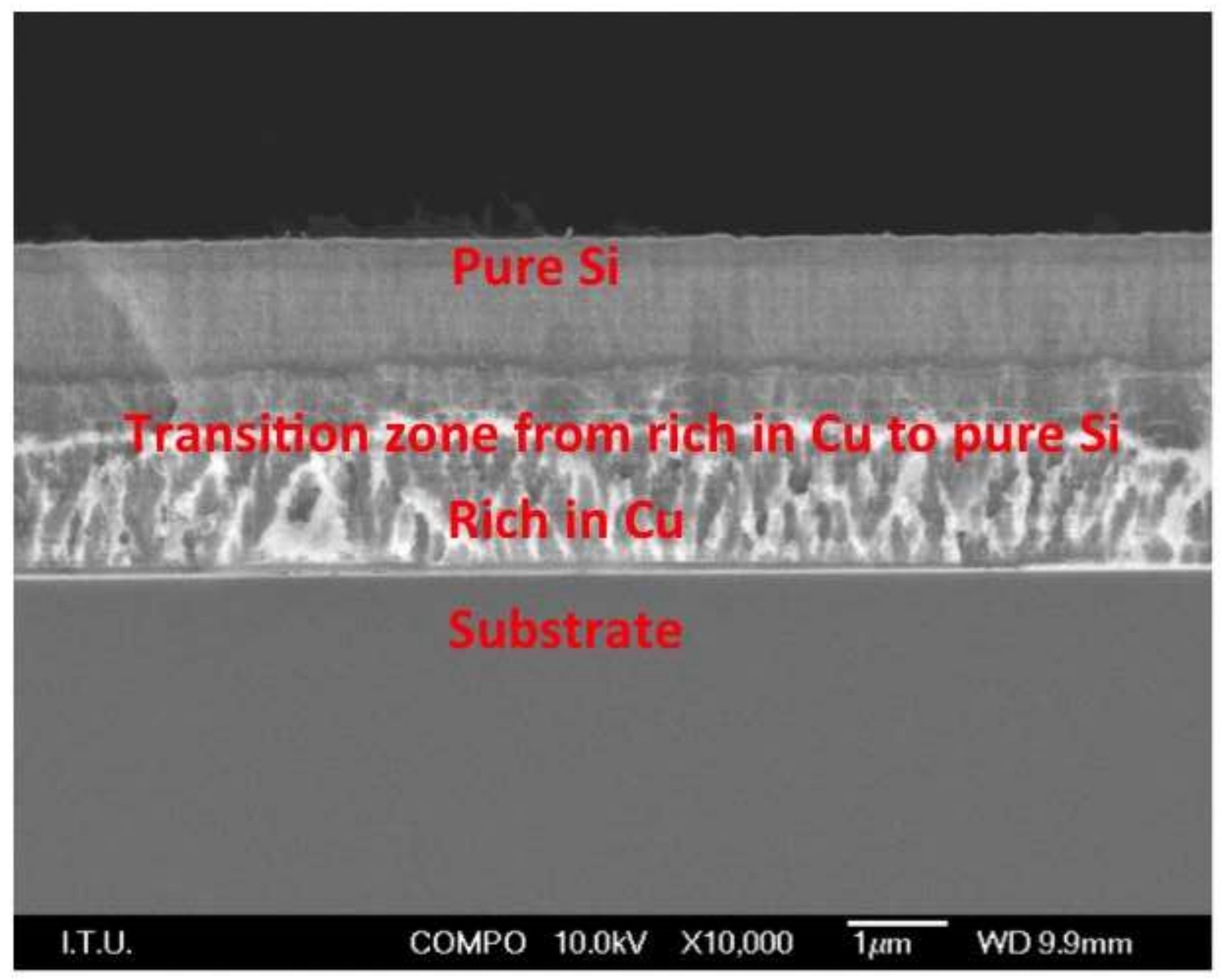




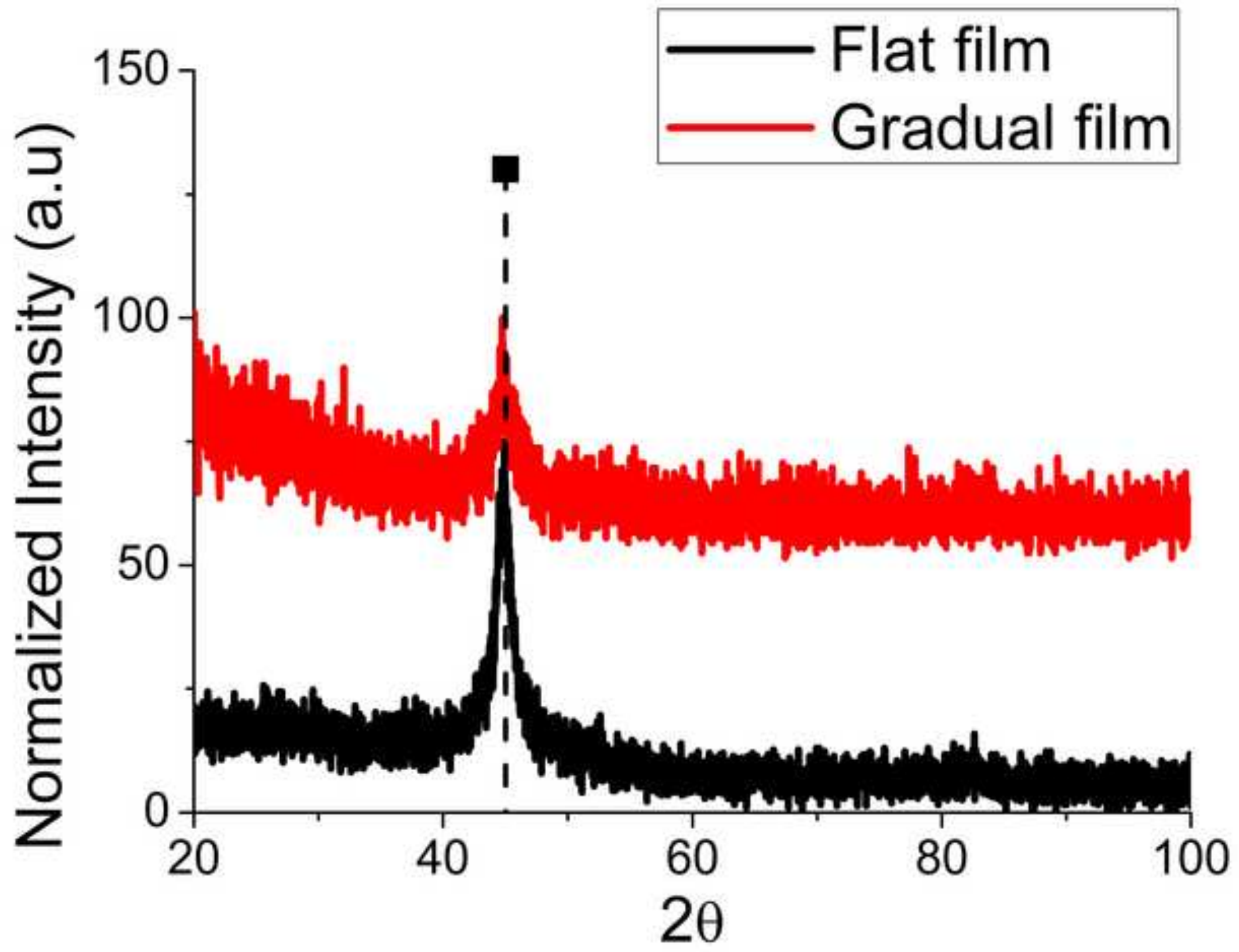




\section{Intensity (a.u.)}

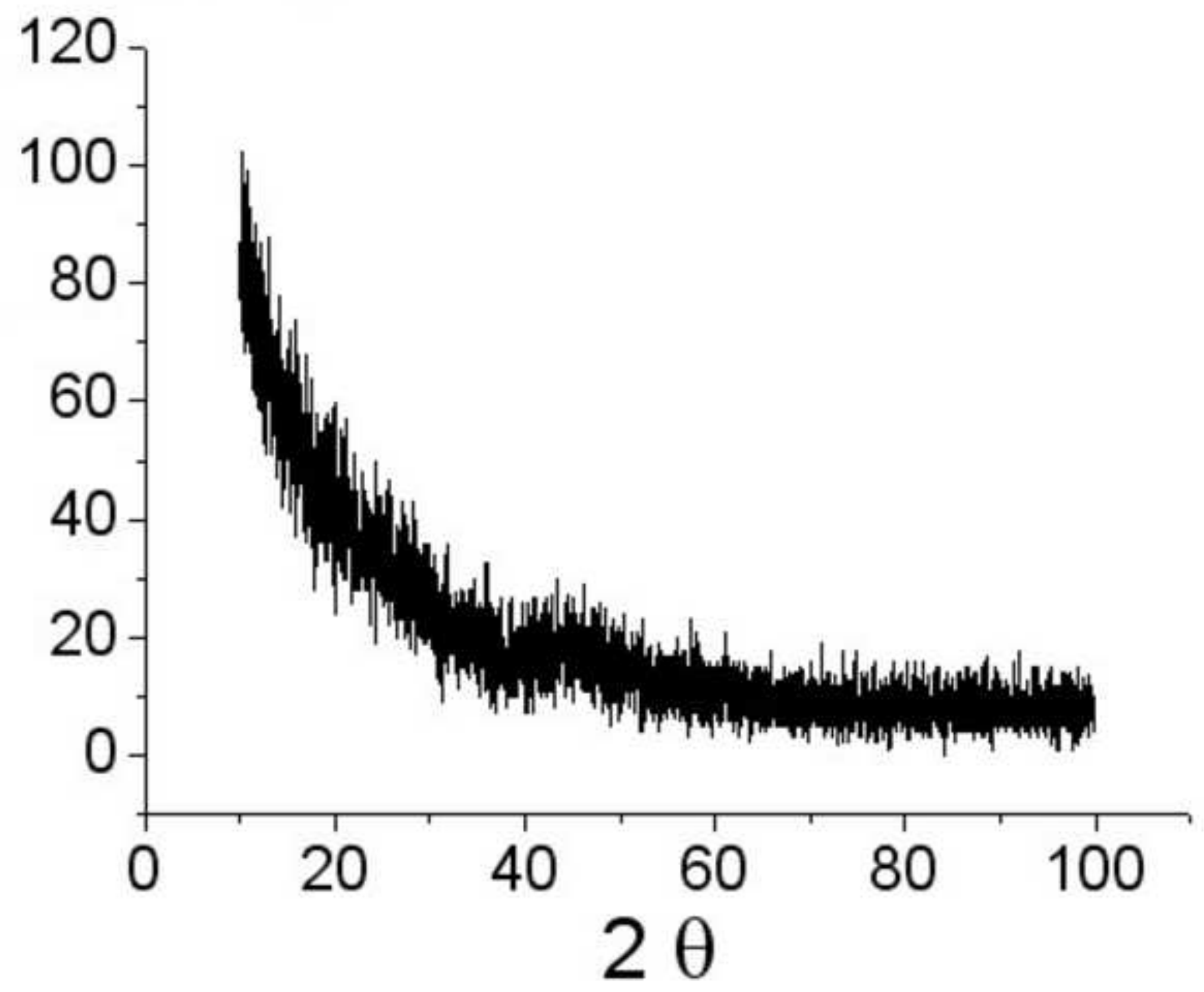



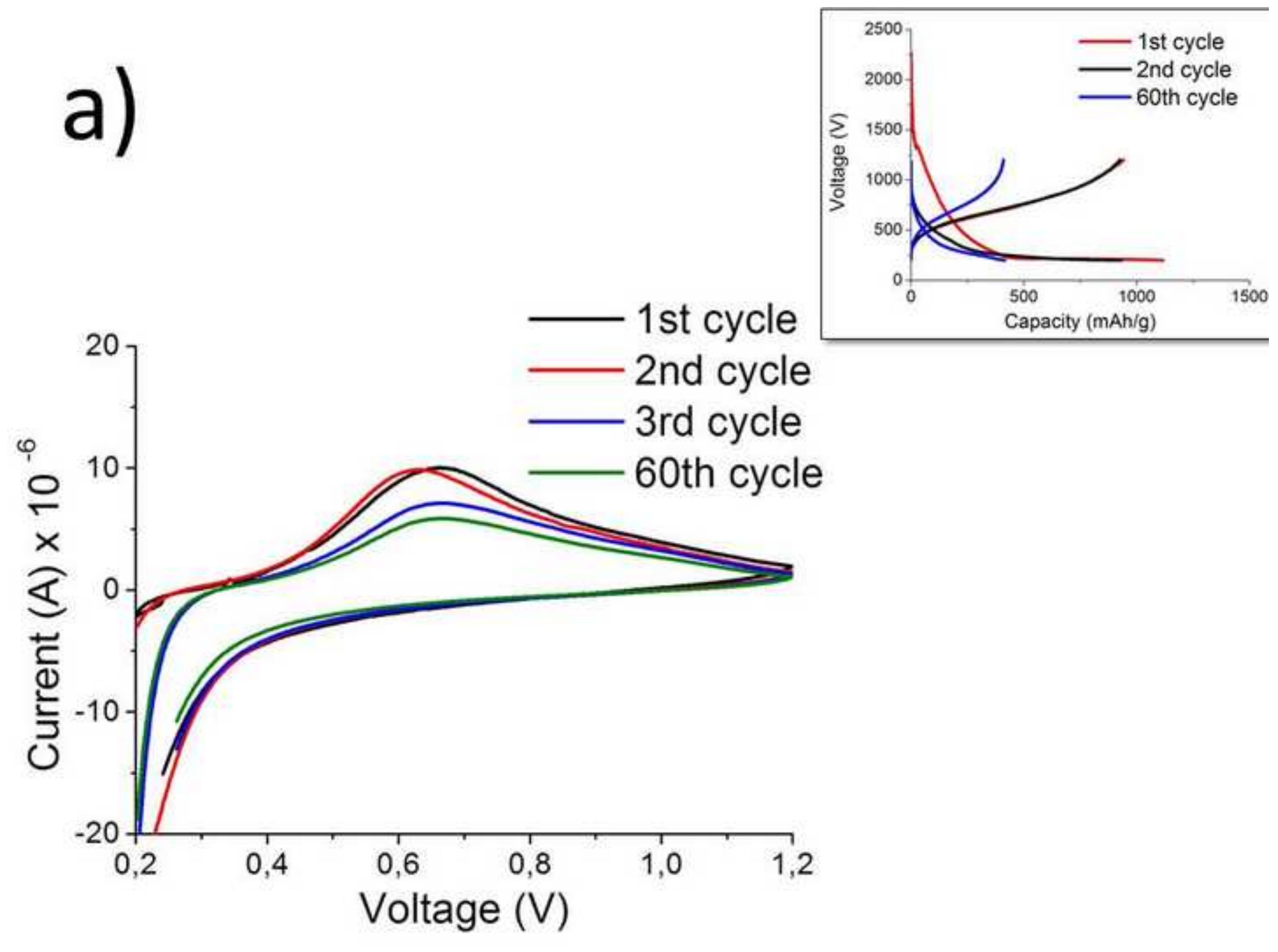

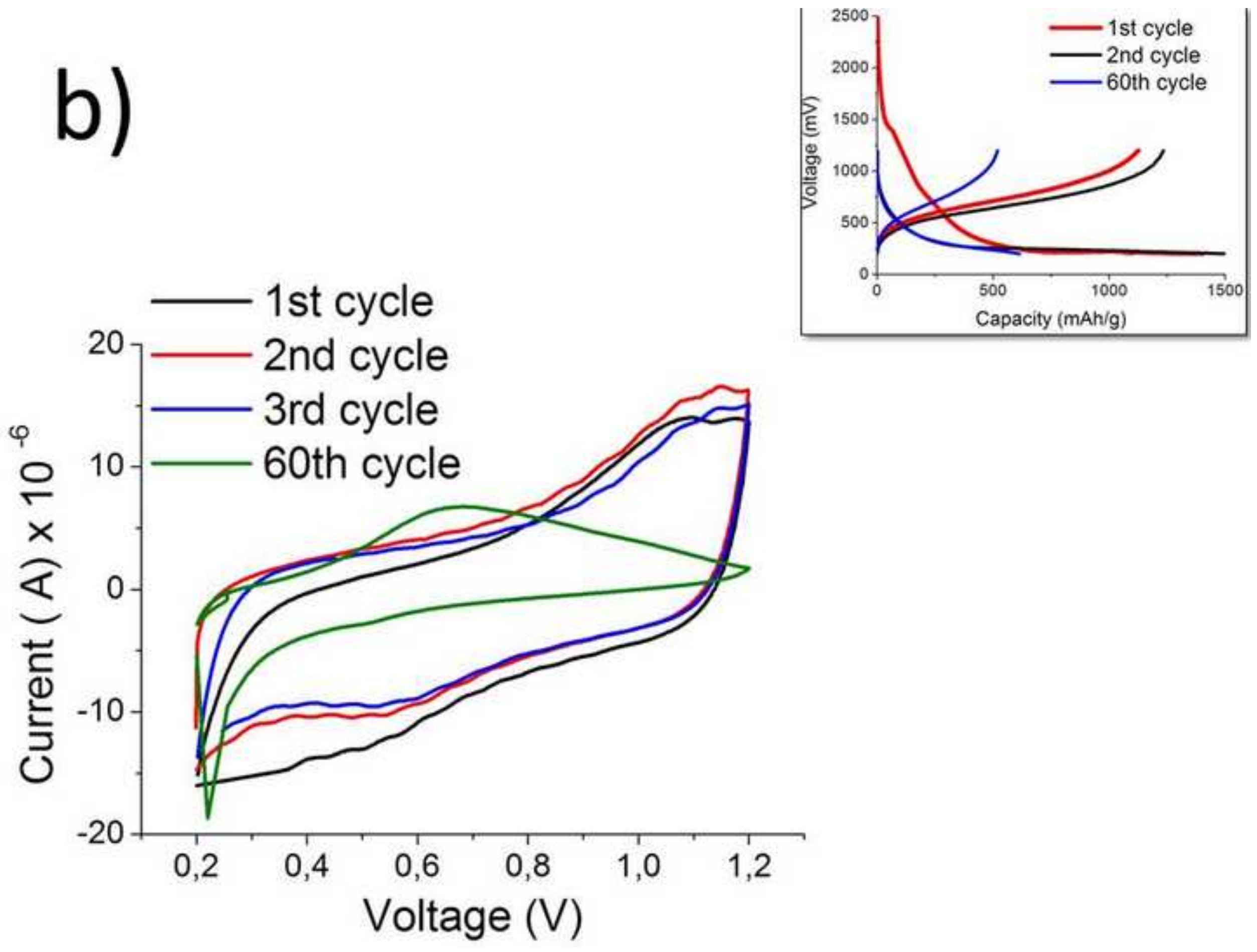


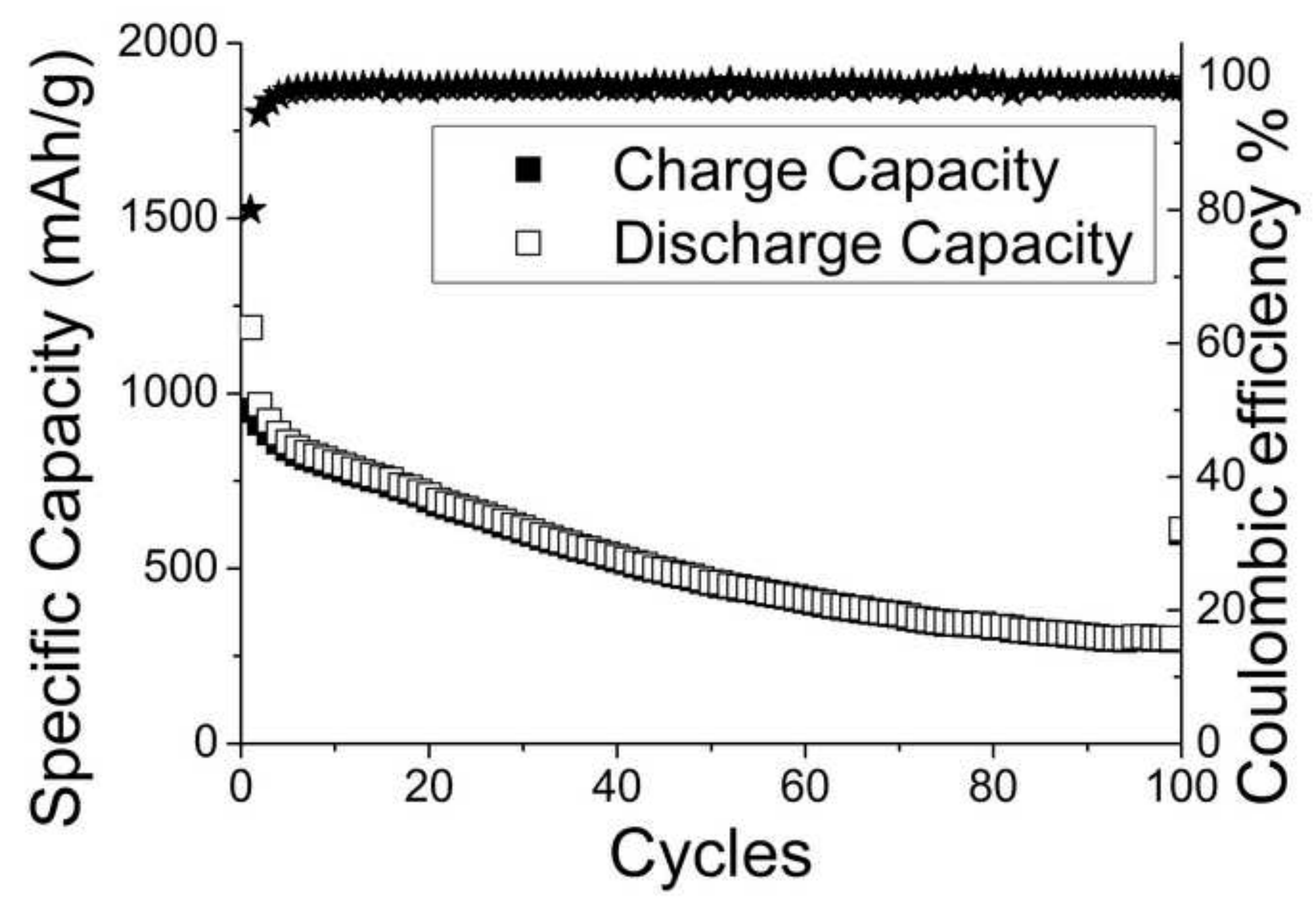




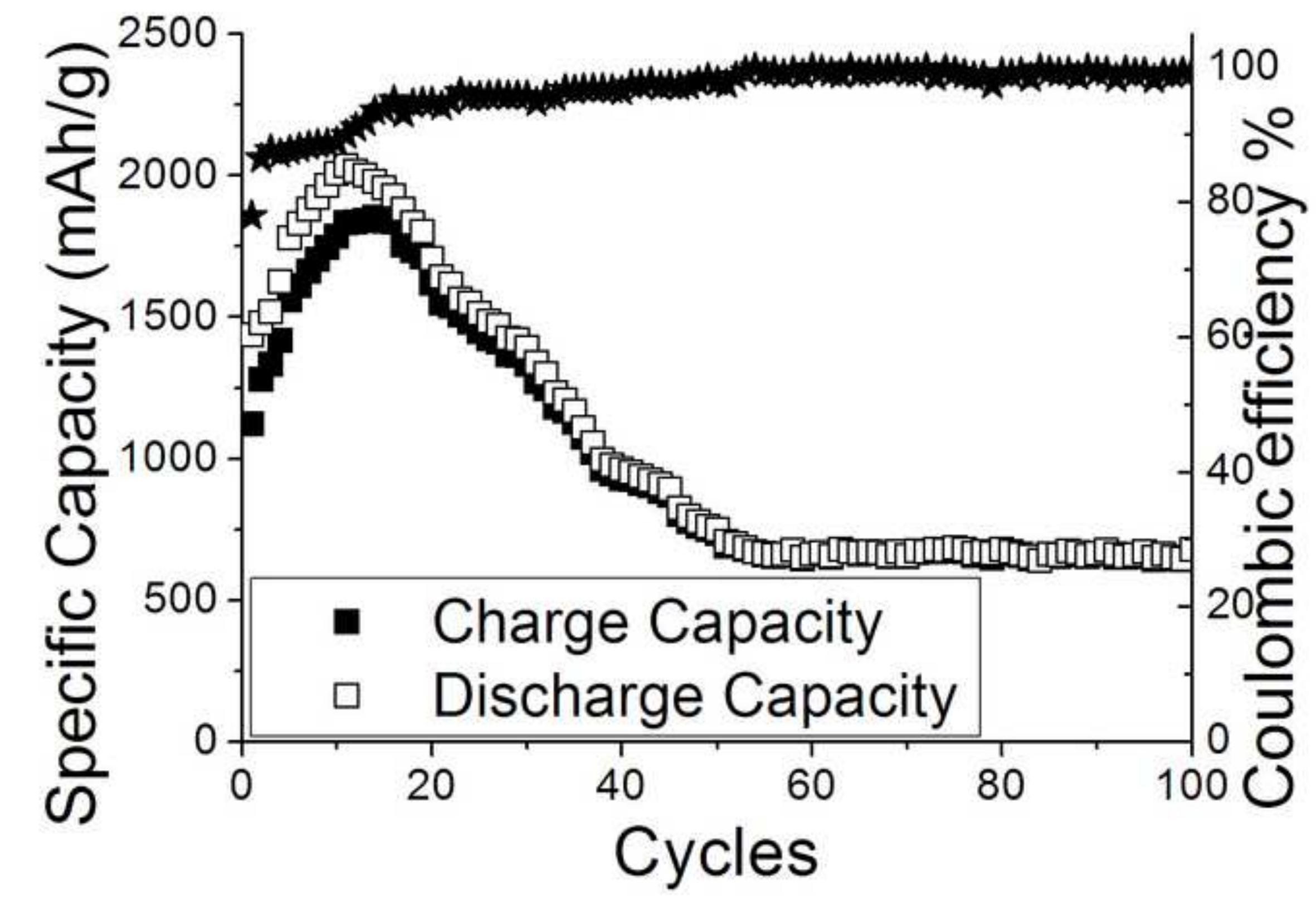


Figure $7 a$

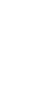

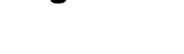

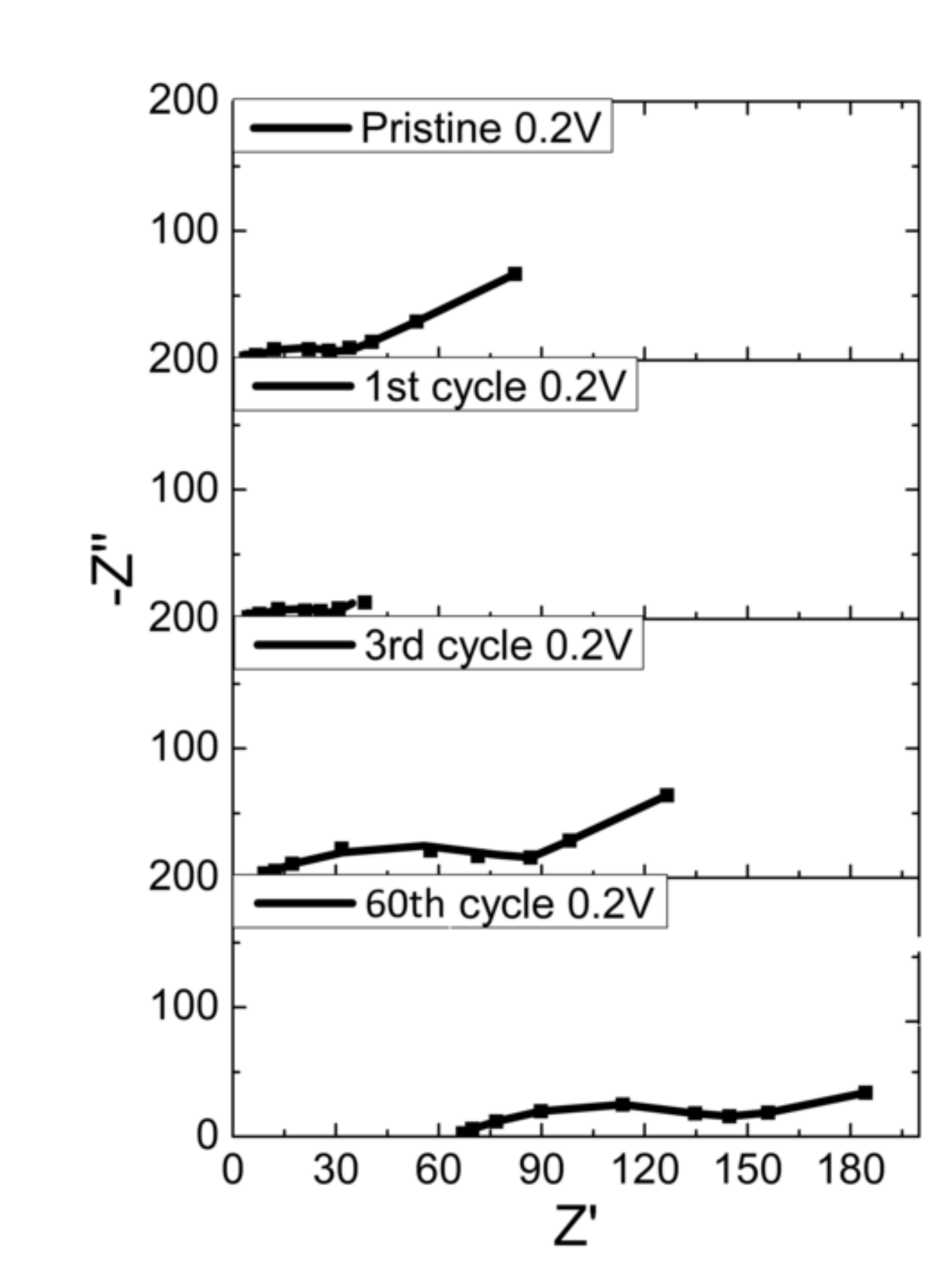

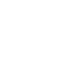
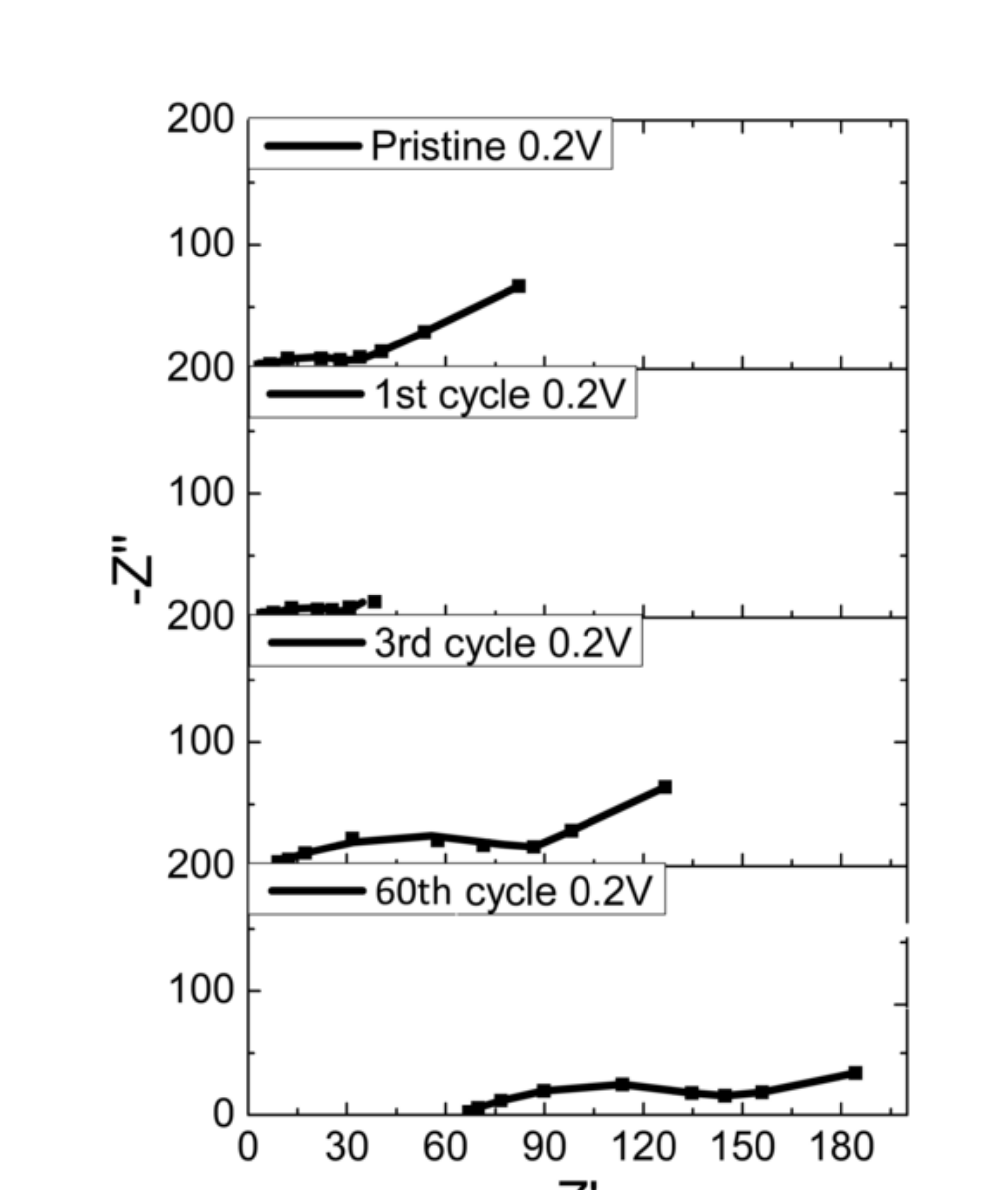


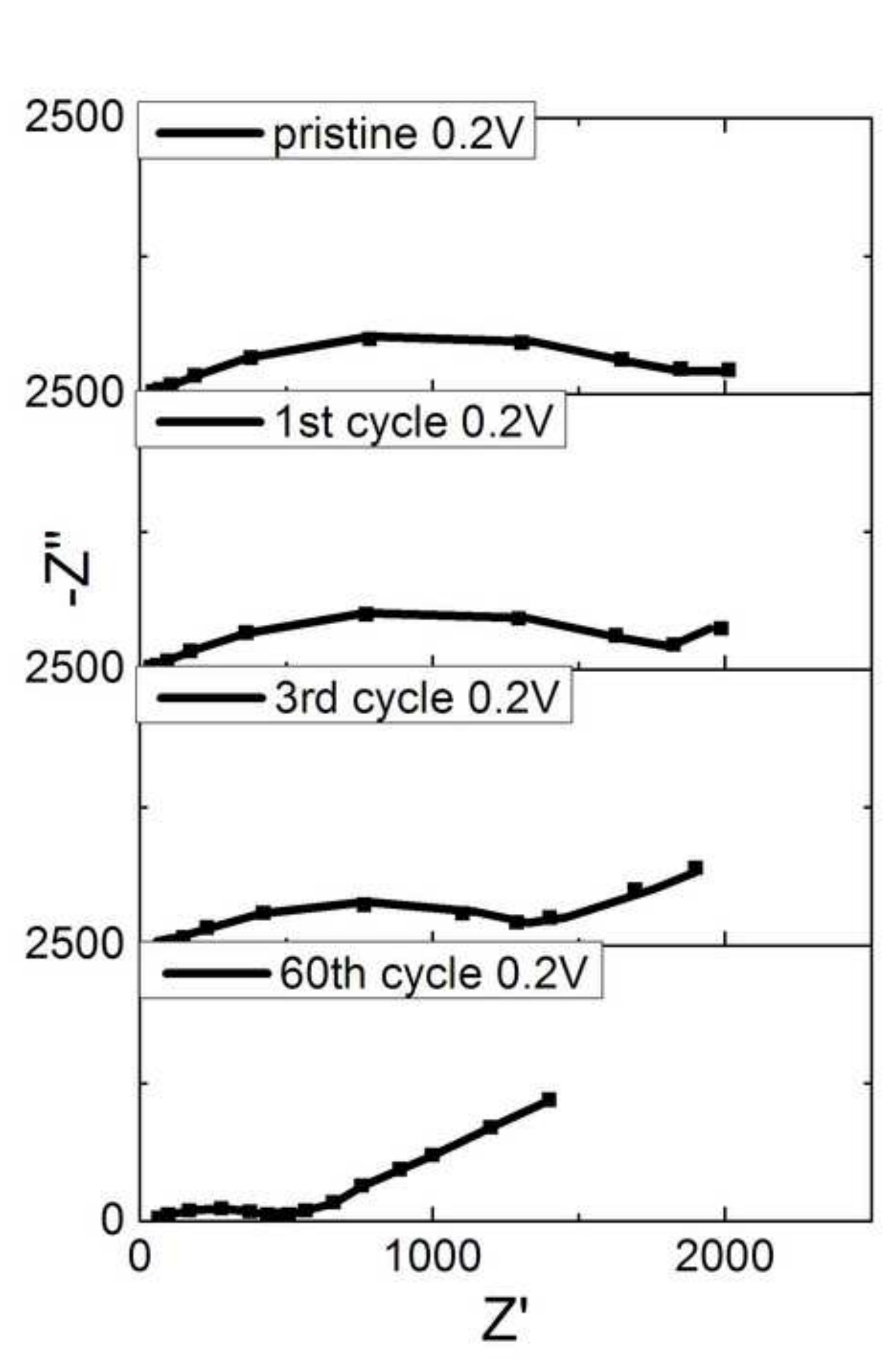

Figure $7 b$

b

\section{.}
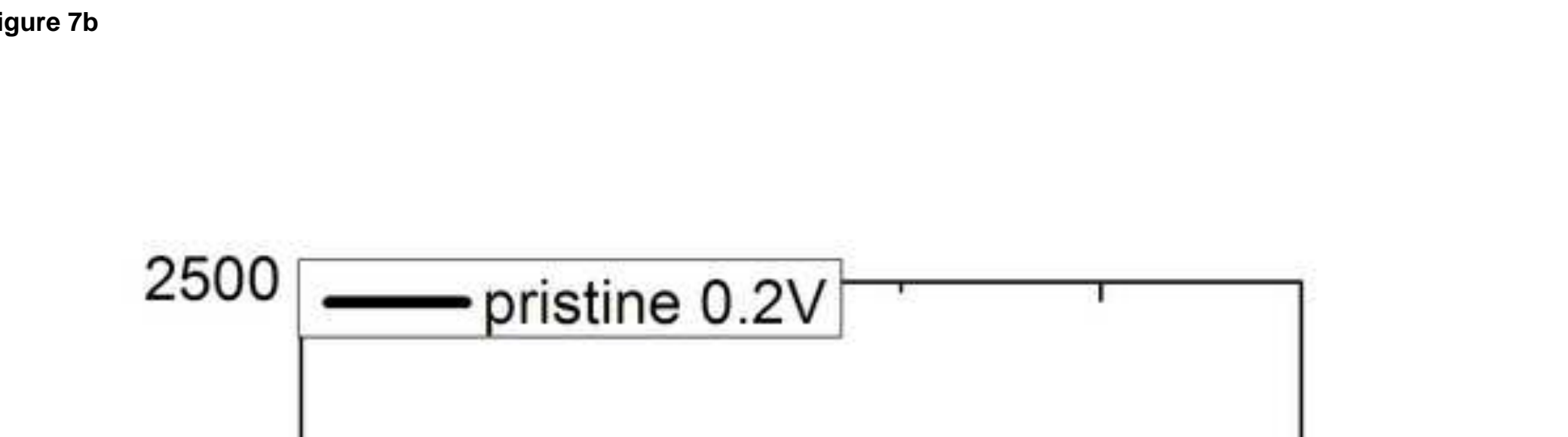


\section{Figure $7 c$}

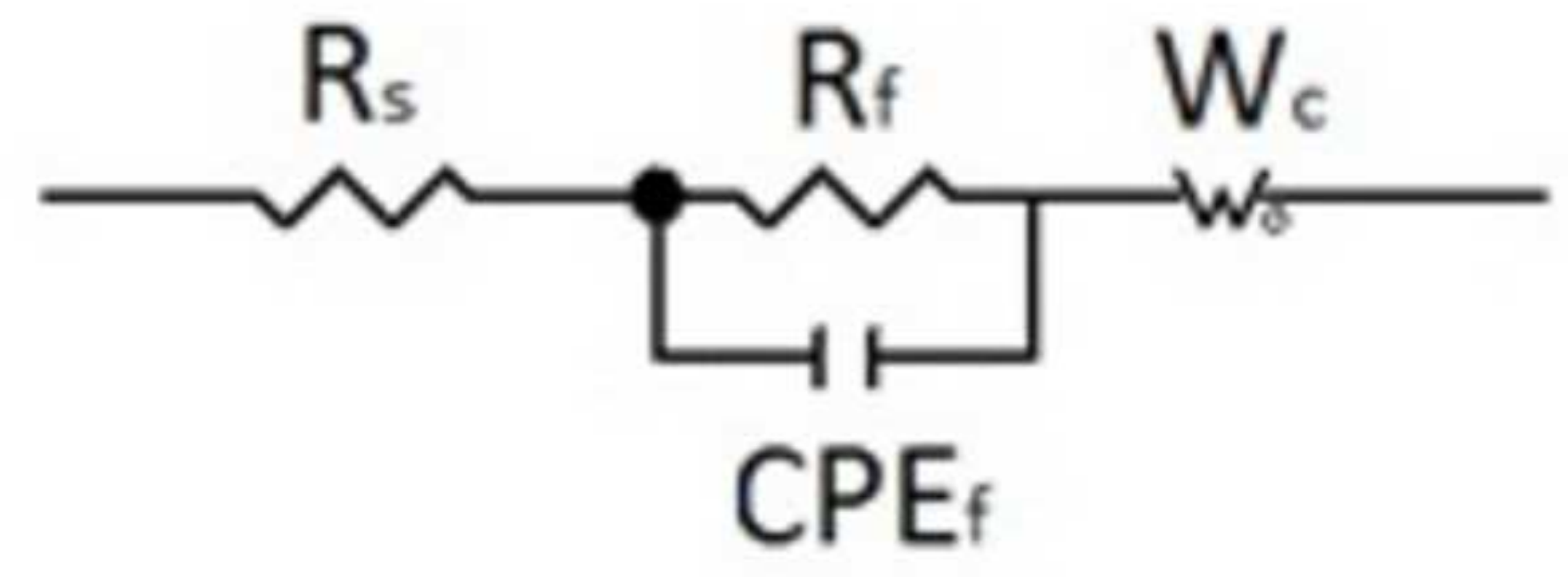

$\begin{array}{lll}R_{s} & R_{f} & W_{c}\end{array}$ $\mathrm{CPE}_{\mathrm{f}}$ 


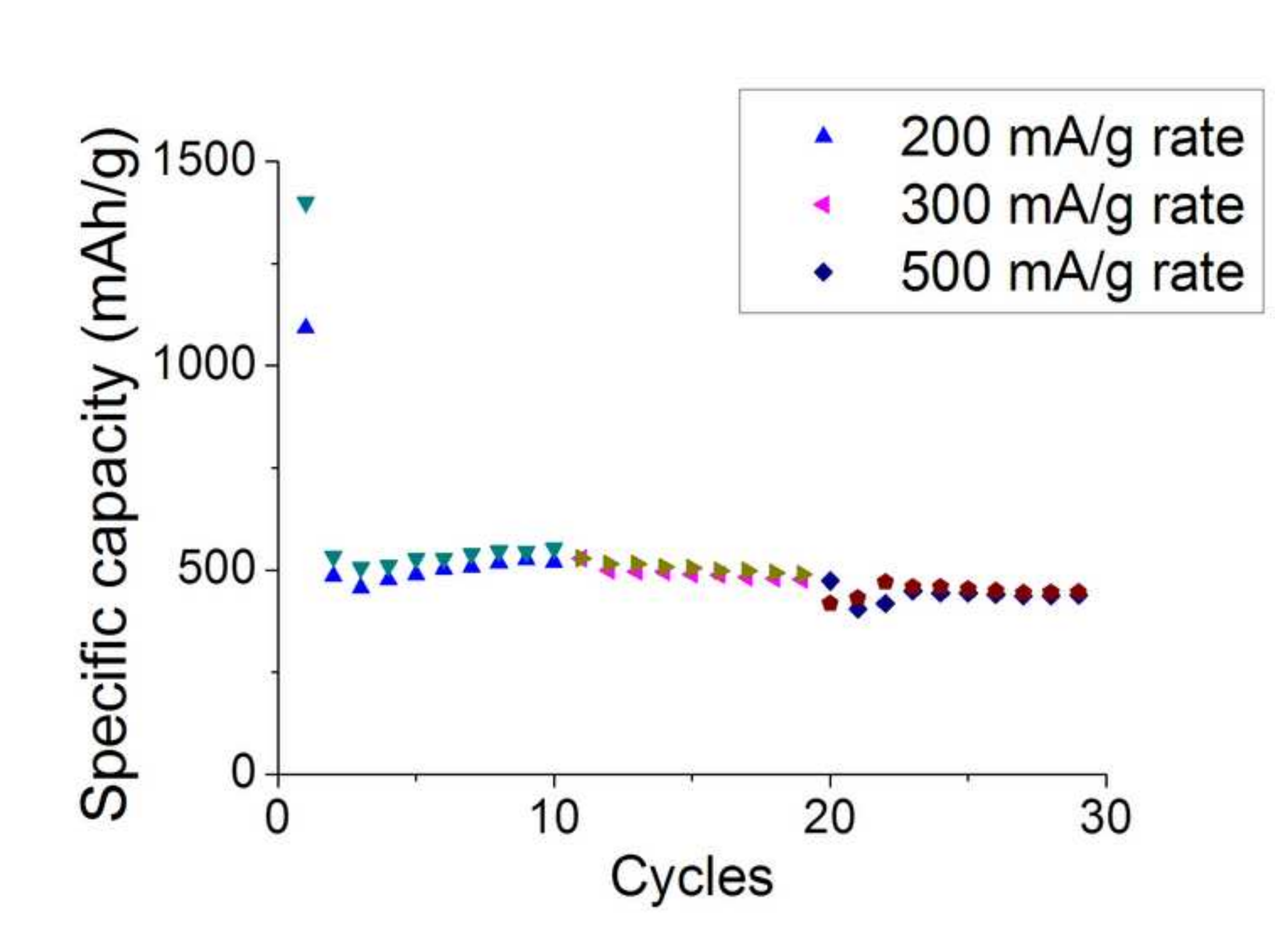


$1^{\text {st }}$ discharge
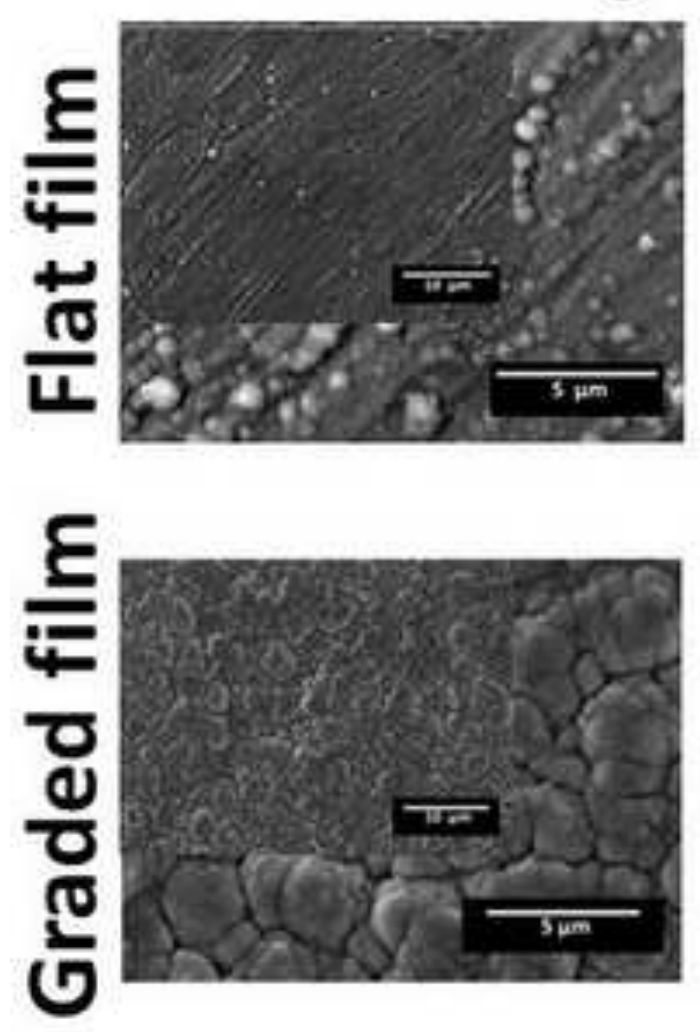

$1^{\text {st }}$ cycle

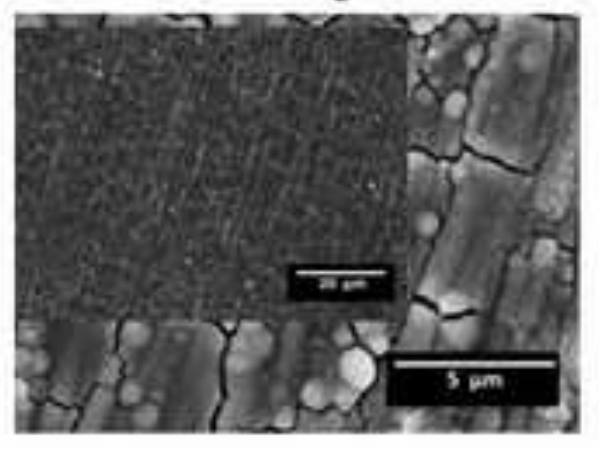

$3^{\text {rd }}$ cycle
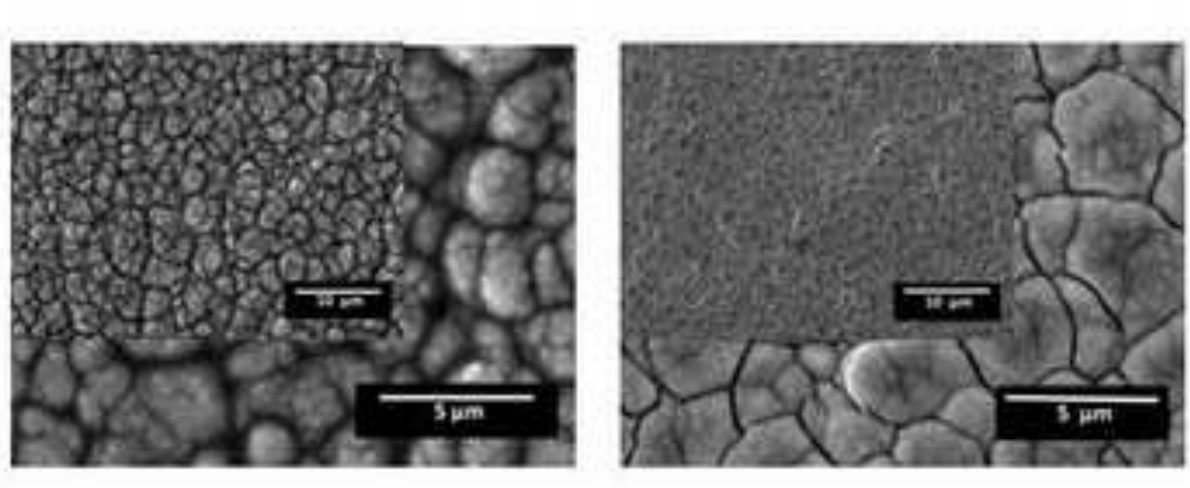

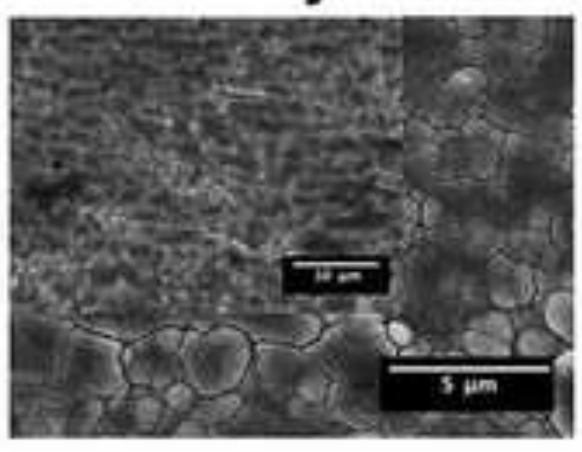

$60^{\text {th }}$ cycle
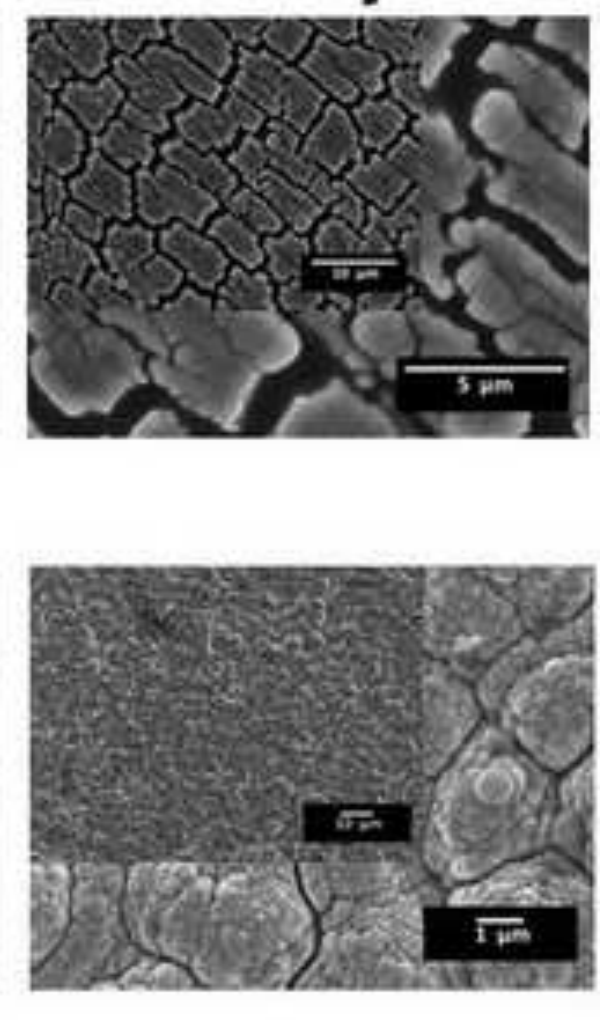